\title{
A Gustatory Neural Circuit of Caenorhabditis elegans Generates Memory-Dependent Behaviors in $\mathrm{Na}^{+}$Chemotaxis
}

\author{
닐. \\ ${ }^{1}$ Department of Biological Sciences, Graduate School of Science, and ${ }^{2}$ CREST, Japan Science and Technology Agency, Kawaguchi, Saitama 332-0012, Japan
}

Animals show various behaviors in response to environmental chemicals. These behaviors are often plastic depending on previous experiences. Caenorhabditis elegans, which has highly developed chemosensory system with a limited number of sensory neurons, is an ideal model for analyzing the role of each neuron in innate and learned behaviors. Here, we report a new type of memory-dependent behavioral plasticity in $\mathrm{Na}^{+}$chemotaxis generated by the left member of bilateral gustatory neuron pair ASE (ASEL neuron). When worms were cultivated in the presence of $\mathrm{Na}^{+}$, they showed positive chemotaxis toward $\mathrm{Na}^{+}$, but when cultivated under $\mathrm{Na}^{+}$-free conditions, they showed no preference regarding $\mathrm{Na}^{+}$concentration. Both channelrhodopsin-2 (ChR2) activation with blue light and up-steps of $\mathrm{Na}^{+}$concentration activated ASEL only after cultivation with $\mathrm{Na}^{+}$, as judged by increase in intracellular $\mathrm{Ca}^{2+}$. Under cultivation conditions with $\mathrm{Na}^{+}$, photoactivation of ASEL caused activation of its downstream interneurons AIY and AIA, which stimulate forward locomotion, and inhibition of its downstream interneuron AIB, which inhibits the turning/reversal behavior, and overall drove worms toward higher $\mathrm{Na}^{+}$concentrations. We also found that the $\mathrm{Gq}$ signaling pathway and the neurotransmitter glutamate are both involved in the behavioral response generated by ASEL.

Key words: ASEL; calcium imaging; klinokinesis; neural circuit; optogenetics; sodium chemotaxis

Significance Statement

Animals have acquired various types of behavioral plasticity during their long evolutionary history. Caenorhabditis elegans prefers odors associated with food, but plastically changes its behavioral response according to previous experience. Here, we report a new type of behavioral response generated by a single gustatory sensory neuron, the ASE-left (ASEL) neuron. ASEL did not respond to photostimulation or upsteps of $\mathrm{Na}^{+}$concentration when worms were cultivated in $\mathrm{Na}^{+}$-free conditions; however, when worms were cultivated with $\mathrm{Na}^{+}$, ASEL responded and inhibited AIB to avoid turning and stimulated AIY and AIA to promote forward locomotion, which collectively drove worms toward higher $\mathrm{Na}^{+}$concentrations. Glutamate and the Gq signaling pathway are essential for driving worms toward higher $\mathrm{Na}^{+}$concentrations.

\section{Introduction}

Animals sense a variety of environmental stimuli and change their behavioral responses according to previous experiences to eventually maximize their chance of survival. To uncover the

Received June 2, 2016; revised Dec. 29, 2016; accepted Jan. 13, 2017.

Author contributions: L.W. and Y.I. designed research; L.W. performed research; H.S., Y.S., M.T., and H.K. contributed unpublished reagents/analytic tools; L.W. analyzed data; L.W. wrote the paper.

This work was supported by Grants-in-Aid for Innovative Area "Memory dynamism" (25115010) and "Comprehensive Brain Network" (22150003) and a Grant-in-Aid for Scientific Research (B) (26291069) to Y.l.; "Mesoscopic Neurocircuitry" to H.K. from the Ministry of Education, Culture, Sports, Science and Technology of Japan; and by "The Salt Science Foundation" (No. 1635) to H.K. We thank Takeshi Ishihara for R-GEC0; Keiko Gengyo-Ando, Junichi Nakai, and Haruhiko Bito for R-CaMP2; Olympus for help in setting up the optogenetics-imaging system used in this research; Manami Kanamori for performing microinjections of R-CaMP2 and R-GECO; and Yu Toyoshima for discussion of optogenetics-imaging experiments.

The authors declare no competing financial interests.

Correspondence should be addressed to Yuichi lino, The University of Tokyo, Science Building No.3, Rm. 224,

2-11-16 Yayoi, Bunkyo-ku, Tokyo 113-0032, Japan. E-mail: iino@bs.s.u-tokyo.ac.jp.

DOI:10.1523/JNEUROSCI.1774-16.2017

Copyright $\odot 2017$ the authors $\quad 0270-6474 / 17 / 372097-15 \$ 15.00 / 0$ versatile roles of sensory systems for sensing environmental stimuli, storing memory, and executing learned behaviors, it is important to examine the characteristics of neurons and molecules and delineate the interactions between them (Bargmann, 2006).

The nematode Caenorhabditis elegans has only 302 neurons in an adult hermaphrodite body, which have been well described, and possesses many genes homologous to those expressed in vertebrate brains, making it an ideal model organism for functional analysis of the nervous system (White et al., 1986). It also has a highly developed chemosensory system that enables it to detect a wide variety of sensory cues (volatile and water-soluble) associated with food, danger, or other animals. It is known that the pair of ASE neurons is responsible for sensing water-soluble chemicals, demonstrated by the fact that simultaneous ablation of all amphid and phasmid neurons except ASE spares chemotaxis (Bargmann and Horvitz, 1991). The ASE neuron class consists of a bilaterally symmetrical pair, ASE-left (ASEL) and ASE-right (ASER), both of which are involved in chemotaxis, but sense differ- 
ent sets of ions. ASEL responds to $\mathrm{Mg}^{2+}, \mathrm{Li}^{+}$, and $\mathrm{Na}^{+}$, whereas ASER responds to $\mathrm{Br}^{-}, \mathrm{I}^{-}$, and $\mathrm{Cl}^{-}$(see Fig. 1a; Ortiz et al., 2009).

C. elegans not only recognizes ions, but also memorizes and learns to move toward or away from certain concentrations of ions according to previous experience. When nematodes are grown in medium containing $\mathrm{NaCl}$ and food, they show attraction to $\mathrm{NaCl}$ via ASE neurons (Kunitomo et al., 2013). However, when they are starved with $\mathrm{NaCl}$, the chemotaxis to $\mathrm{NaCl}$ falls dramatically or even becomes negative to avoid $\mathrm{NaCl}$ (Tomioka et al., 2006; Adachi et al., 2010).

Two behavioral mechanisms have been reported for salt chemotaxis: klinokinesis, in which worms change the direction of locomotion quickly with pirouettes (sharp turns) (Pierce-Shimomura et al., 1999) and klinotaxis, in which worms gradually curve toward higher (or lower) salt concentrations (Iino and Yoshida, 2009). In klinokinesis, worms increase their rate of pirouettes either when salt concentration decreases (driving positive chemotaxis) or when salt concentration increases (driving negative chemotaxis). ASEL and ASER neurons have lateralized functions: the ASEL neuron is stimulated by increased salt concentration and promotes forward locomotion and the ASER neuron is stimulated by decreased salt concentration and promotes either forward or turning behaviors (see Fig. 1a; Suzuki et al., 2008; Kunitomo et al., 2013). The Gq/ diacylglycerol (DAG)/protein kinase C (PKC) pathway acts in ASER to promote migration to higher salt concentrations, possibly by augmenting the AIB response (Kunitomo et al., 2013). It was also reported that ASER-evoked curving toward lower concentrations is mediated by AIY interneurons (Satoh et al., 2014).

In contrast, the role and properties of the ASEL neuron in salt chemotaxis plasticity has not yet been examined thoroughly, although our previous study showed that, together with ASER, ASEL is important for $\mathrm{NaCl}$ chemotaxis learning (Adachi et al., 2010). To keep balance between external and internal conditions in the body, C. elegans, much like flies (Zhang et al., 2013) and mammals (Chandrashekar et al., 2010), prefers relatively low $\mathrm{NaCl}$ concentrations (Saeki et al., 2001; Bargmann, 2006). ASE neurons play the main role in salt chemotaxis at low concentrations of $\mathrm{NaCl}$ ( $<200 \mathrm{~mm}$; Hukema et al., 2008). It has been also reported that, when ASEL senses a high external concentration of salt (750 mM), it releases INS-6 to AWC neurons to recruit them to act as interneurons for ASEL (Leinwand and Chalasani, 2013). Here, we investigate $\mathrm{Na}^{+}$chemotaxis systematically and reveal that ASEL generates a new type of memory-dependent behavioral plasticity in $\mathrm{Na}^{+}$chemotaxis. ASEL showed no response after $\mathrm{Na}^{+}$-free cultivation, but was activated after cultivation with $\mathrm{Na}^{+}$, released glutamate to activate AIY and AIA to stimulate forward movement, inhibited AIB to prevent turning behavior, and ultimately drove worms to higher concentrations of $\mathrm{Na}^{+}$.

\section{Materials and Methods}

Strains and culture. All animals used in this study were hermaphrodites and were cultivated at $20^{\circ} \mathrm{C}$ under standard conditions (Brenner, 1974) except one strain. This strain (SRS281; Table 1) was cultivated at $25^{\circ} \mathrm{C}$ as described by Kocabas et al., 2012 and Satoh et al., 2014. All C. elegans strains were derived from the wild-type strain Bristol N2. All strains used for optogenetics carried the lite-1(ce314) mutation to diminish the innate avoidance of blue light (Edwards et al., 2008; Ward et al., 2008; Liu et al., 2010; Li et al., 2014). Fast-growing E. coli NA22 was used as food source in behavioral assays and chemotaxis assays to avoid starvation (Tomioka et al., 2006; Adachi et al., 2010; Kunitomo et al., 2013). OP50 was used for imaging experiments because animals cultivated with NA22 tended to exhibit high background fluorescence in the intestine (Oda et al., 2011; Kunitomo et al., 2013). The C. elegans strains and transgenic lines used in this study are listed in Table 1. ASEL-, AWC-, AIY-, AIA- and AIB-ablated animals were described previously (Table 1; Adachi et al., 2010; Yoshida et al., 2012; Kunitomo et al., 2013; Satoh et al., 2014).

Chemotaxis assay and tracking assay. To evaluate animals' behaviors on an $\mathrm{Na}^{+}$gradient, a modified chemotaxis assay was used. Test plates were prepared as shown in Figure $1 b$. The background agar was $8.5 \mathrm{~cm}$ in diameter and $1.76 \mathrm{~mm}$ in thickness $(10 \mathrm{ml}$ of solution was poured) and included $100 \mathrm{mM} \mathrm{NH}_{4} \mathrm{Cl}, \mathrm{pH} 6.0$, and $2 \%$ agar in chemotaxis buffer $(25$ mM potassium phosphate, $\mathrm{pH} 6.0,1 \mathrm{~mm} \mathrm{CaCl}_{2}, 1 \mathrm{~mm} \mathrm{MgSO}_{4}$ ). On top of the plate, two cylindrical agar blocks, each $14.5 \mathrm{~mm}$ in diameter and 5.3 $\mathrm{mm}$ in thickness, including either $100 \mathrm{~mm} \mathrm{NaCl}$ (A site) or $100 \mathrm{~mm}$ $\mathrm{NH}_{4} \mathrm{Cl}$ (B site) and 2\% agar in chemotaxis buffer, were placed for $24 \mathrm{~h}$ at $20^{\circ} \mathrm{C}$ and removed just before assay. This procedure created a concentration gradient on the test plate with a $\mathrm{Na}^{+}$concentration of $45 \mathrm{~mm}$ at point $\mathrm{A}, 5 \mathrm{~mm}$ at point $\mathrm{C}$, and $0 \mathrm{~mm}$ at point $\mathrm{B}$ and $\mathrm{a} \mathrm{NH}_{4}{ }^{+}$concentration of 65 $\mathrm{mm}$ at point $\mathrm{A}, 95 \mathrm{~mm}$ at point $\mathrm{C}$, and $100 \mathrm{~mm}$ at point $\mathrm{B}$ based on a numerical simulation of diffusion (Iino and Yoshida, 2009; Kunitomo et al., 2013). $\mathrm{NH}_{4}{ }^{+}$is mainly sensed by AWC neurons (Frøkjær-Jensen et al., 2008) and our results using an AWC-ablated strain showed that the $\mathrm{NH}_{4}{ }^{+}$ion was not responsible for the chemotaxis observed in this study (see Fig. 1c). Therefore, this assay format is viable for testing $\mathrm{Na}^{+}$chemotaxis. Animals were grown to young adults on standard nematode growth medium (NGM), and then transferred to NGM plates either without $\mathrm{Na}^{+}$or with $100 \mathrm{mM} \mathrm{Na}^{+}$for preassay cultivation for $6 \mathrm{~h}$. One hundred to 200 animals were washed out from the plates and placed at the center of test plates (C point) (see Fig. $1 b$ ). One microliter each of 0.5 $\mathrm{M} \mathrm{NaN}$ was spotted on points $\mathrm{A}$ and $\mathrm{B}$ of test plates just before the start of each assay. Animals were allowed to move for $45 \mathrm{~min}$ and the plates were chilled at $4^{\circ} \mathrm{C}$ before counting. Animals within a $2 \mathrm{~cm}$ radius from the center of each agar block were considered to be attracted and those within a $1 \mathrm{~cm}$ radius from the start point were excluded from the total number of animals to calculate the chemotaxis index (CI) as follows:

$$
\mathrm{CI}=\frac{\text { Number of worms at } \mathrm{A} \text { area }- \text { Number of worms at B area }}{\text { all number of worms on the plates }- \text { Number of worms at } \mathrm{C} \text { area }}
$$

\section{Movement index}

$$
=\frac{\text { Number of worms at A area }+ \text { Number of worms at B area }}{\text { all number of worms on the plates }}
$$

The tracking assay was performed as described previously (Iino and Yoshida, 2009; Yoshida et al., 2012; Kunitomo et al., 2013) with some modifications. Thirty to 50 animals were washed out from culture plates with $100 \mathrm{~mm} \mathrm{NaCl}$ and placed at the center of test plates and then chemotaxis was tested as described above (see Fig. $1 b$ ). Images of the whole test plate were captured for $15 \mathrm{~min}$ at $1 \mathrm{frame} / \mathrm{s}$. Individual animals were tracked on the images and pirouette events were detected. $\mathrm{Na}^{+}$concentration on the test plate was estimated by numerical simulation as above and pirouette frequency was calculated for each $0.1 \mathrm{~mm} / \mathrm{s}$ bin of the time derivative of $\mathrm{Na}^{+}$concentration (dC/dT) (Iino and Yoshida, 2009). Bins with fewer than 20 data points were omitted from analyses. Data from 150-600 s were used to calculate the pirouette frequency. The experiment was repeated independently 13 times.

Optogenetic stimulation and behavioral assay. Behavioral response to photostimulation was quantified as described previously (Kunitomo et al., 2013) with some modifications. Briefly, young adults grown on standard NGM plates were further cultivated overnight under various salt concentrations supplemented with $10 \mu \mathrm{M}$ all-trans retinal (ATR; SigmaAldrich). Worms cultivated under various salt concentrations without ATR were used as controls. Their behavior was tested on retinal-free chemotaxis plates without a salt gradient. Pulses of blue light (peak wavelength $470 \mathrm{~nm} ; 0.2 \mathrm{~mW} / \mathrm{mm}^{2}$ ) of a fixed length between 1 and $60 \mathrm{~s}$, depending on the experiment, were delivered by a ring-shaped lightemitting diode after $2 \mathrm{~min}$ of recording without light. For each animal, light pulses were applied five times, with $80 \mathrm{~s}$ intervals between each pulse. Locomotion was monitored by the multiworm tracking system. The nonforward probability was calculated as the ratio of animals that were performing pirouettes, sharp turns, or pauses (collectively called nonforward) at each time point. At least six independent experiments 
Table 1. C. elegans strains and transgenic lines used in this study

\begin{tabular}{|c|c|c|}
\hline Strain & Genotype & Description \\
\hline Bristol N2 & C.eleganswild-type & Wild-type \\
\hline Genetic ablation of neurons & wis\#3 Is [odr-1(gcy-10)::m Casp, odr-1(gcy-10)::GFP, mec-4::GFP $]$ & Genetic ablation of AWC \\
\hline OH8585 & $\begin{array}{l}\text { otls4[gcy-7p::gfp]; otEx3822[ceh-36::CZ-caspase3(p17), gcy-7:: } \\
\quad \text { caspase3(p12)-NZ, myo-3::mCherry] }\end{array}$ & Genetic ablation of ASEL \\
\hline JN580 & pels580 [ins-1(short)p::casp 1; ins-1(short)p::venus unc-122p::gfp] & Genetic ablation of AIA \\
\hline JN579 & pels579[ttx-3p:::casp1 ttx-3p::venus lin-44p:::gfp] & Genetic ablation of AIY \\
\hline JN578 & pels578 [npr-9p::casp1 npr-9p:::venus unc-122p::mCherry] & Genetic ablation of AIB \\
\hline JN1693 & $\begin{array}{l}\text { pels579[ttx-3p::mcasp1 ttx-3p::venus lin-44p:::gfp]; pels580[ins-1 } \\
\text { (short)p::mcasp1 ins-1(short)::venus unc-122p:::gfp] }\end{array}$ & Genetic ablation of AIY and AIA \\
\hline JN604 & $\begin{array}{l}\text { pels578 [npr-9p:::casp1 npr-9p::venus unc-122p::mCherry]; pels579 } \\
\text { [ttx-3p:::casp1 ttx-3p::venus lin-44p:::gfp] }\end{array}$ & Genetic ablation of AIY and AIB \\
\hline JN605 & $\begin{array}{l}\text { pels578 [npr-9p:::casp1 npr-9p::venus unc-122p::mCherry]; pels580 } \\
\text { [ins-1(short)p::casp1 ins-1(short):::gfp unc-122p:::gfp] }\end{array}$ & Genetic ablation of AIB and AIA \\
\hline JN1694 & $\begin{array}{l}\text { pels578[npr-9p:::mcasp1 npr-9p::venus unc-122p::mcherry]; pels579 } \\
\text { [ttx-3p:::mcasp1 ttx-3p::venus lin-44p:::gfp]; pels580 } \\
\text { [ins-1(short)p::mcasp1 ins-1(short)p::venus unc-122p::gfp] }\end{array}$ & Genetic ablation of AIY, AIA, and AIB \\
\hline \multicolumn{3}{|l|}{ Optogenetics } \\
\hline JN1695 & lite-1(ce314) X; pels1095[gcy-7p::ChR2::venus unc-122p:::mCherry] & Optical stimulation of ASEL \\
\hline JN1621 & $\begin{array}{l}\text { lite-1(ce314) X; pels1095[gcy-7p::ChR2:::venus unc-122p:::mCherry]; pels578 } \\
\text { [npr-9p:::casp1 npr-9p:::venus unc-122p:::mCherry] }\end{array}$ & Optical stimulation of ASEL under genetic ablation of AIB \\
\hline JN1622 & $\begin{array}{l}\text { lite-1(ce314) X; pels1095[gcy-7p::ChR2::venus unc-122p:::mCherry]; pels579 } \\
\text { [ttx-3p:::casp1 ttx-3p:::venus lin-44p:::gfp] }\end{array}$ & Optical stimulation of ASEL under genetic ablation of AIY \\
\hline JN1623 & $\begin{array}{l}\text { lite-1(ce314) X; pels1095[gcy-7p::ChR2:::venus unc-122p:::mCherry]; pels580 } \\
\text { [ins-1 (short)p:::casp1 ins-1(short)p::venus unc-122p:::gfp] }\end{array}$ & Optical stimulation of ASEL under genetic ablation of AIA \\
\hline JN1696 & lite-1(ce314) X; Ex[npr-9p:::ChR2 unc-122p::mcherry] & Optical stimulation of AIB \\
\hline JN1605 & lite-1(ce314) X; Ex[ins-1 (short)p::ChR2 unc-122p:::m Cherry] & Optical stimulation of AIA \\
\hline JN1697 & lite-1(ce314) X; Ex[ttx-3p:::ChR2 unc-122p::mcherry](\#1) & Optical stimulation of AIY ("\#1 strain") \\
\hline SRS281 & $\begin{array}{l}\text { lite-1(ce314) X; pha-1 (e2123) III; sraEx281[ttx-3p::chop2(H134R):: } \\
\quad \text { TagRFP + pBX(pha-1(+))] }\end{array}$ & Optical stimulation of AIY ("\#2 strain") \\
\hline JN1699 & $\begin{array}{l}\text { lite-1(ce314) X; pels1095 [gcy-7p:::ChR2::venus unc-122p:::mCherry]; } \\
\text { dyf-11(pe554) X;Ex[gcy-7p::venus:::dyf-11(+); ; myo-3p::VVenus] }\end{array}$ & Optical stimulation of ASEL; ASEL-specific rescue of dyf-11 (pe554) \\
\hline JN1698 & lite-1(ce314) dyf-11 (pe554) X; pels 1095 [gcy-7p::ChR2::venus unc-122p::mCherry] & Optical stimulation of ASEL; dyf-11(pe554) background \\
\hline JN1701 & $\begin{array}{l}\text { lite-1(ce314) X; pels1095[gcy-7p::ChR2::venus unc-122p::m Cherry]; Ex[gcy-7p::egl-30 } \\
\text { (Y61N) myo-3::venus] }\end{array}$ & Optical stimulation of ASEL; ASEL-specific gain of function of egl-30 \\
\hline JN1624 & lite-1(ce314) X; pels1095[gcy-7p:::ChR2::venus unc-122p:::mCherry]; eat-4(ky5)III & Optical stimulation of ASEL; eat-4(ky5)III background \\
\hline JN1629 & $\begin{array}{l}\text { lite-1(ce314) X; pels1095[gcy-7p:::ChR2::venus unc-122p::mCherry]; } \\
\text { Ex[gcy-7p::eat-4(RNAi); myo-3p::venus] }\end{array}$ & Optical stimulation of ASEL; ASEL-specific RNAi of eat-4 \\
\hline \multicolumn{3}{|l|}{ Imaging and optogenetics } \\
\hline JN609 & $\begin{array}{l}\text { lite-1(ce314) X; pels1095[gcy-7p::ChR2::venus unc-122p::mCherry]; Ex[npr-9p:: } \\
\quad \text { RCaMP2; lin-44:::gfp] }\end{array}$ & Imaging of AIB under photoactivation of ASEL \\
\hline JN610 & $\begin{array}{l}\text { lite-1(ce314) X; pels1095[gcy-7p::ChR2::venus unc-122p::mCherry]; Ex[ttx-3p:: } \\
\quad \text { RCaMP2; lin-44:::gfp] }\end{array}$ & Imaging of AIY under photoactivation of ASEL \\
\hline JN608 & $\begin{array}{l}\text { lite-1(ce314) X; pels1095[gcy-7p::ChR2:::venus unc-122p::mCherry]; Ex[ins-1p:: } \\
\quad \text { RGEC0; lin-44::gfp] }\end{array}$ & Imaging of AIA under photoactivation of ASEL \\
\hline JN611 & $\begin{array}{l}\text { lite-1(ce314) X; pels1095[gcy-7p::ChR2::venus unc-122p:::mCherry]; Ex[gcy-7p:: } \\
\quad \text { RCaMP2; lin-44:::gfp] }\end{array}$ & Imaging of ASEL under photoactivation of ASEL \\
\hline
\end{tabular}

were performed for each condition. The average nonforward probability in a $21 \mathrm{~s}$ window before stimulation (typically, time $-30 \mathrm{~s}$ to $-10 \mathrm{~s}$ ) was set as NS (for "no stimulation"); the average nonforward probability around the peak value in a $5 \mathrm{~s}$ window ( $3 \mathrm{~s}$ for AIY\#1; see Figs. $3 g, 5 d, e$ ) during stimulation [typically, time 3-7 s (2-4 s for AIY\#1)] was set as DS (for "during stimulation"); therefore, the change of nonforward probability during stimulation equals NS subtracted from DS.

Calcium imaging upon photoactivation. Plasmids for germline transformation were generated by the Gateway system (Invitrogen) in which the LR reaction using Gateway LR Clonase (Invitrogen) was used to combine the promoter sequence on an entry vector and the open reading frame of the gene of interest on a destination vector. Details of this method have been described previously (Matsuki et al., 2006; Kunitomo et al., 2013). pENTR-gcy-7p, pENTR-npr-9p, pENTR-ttx-3p, pENTR-ins1 (short) $p$ have also been described previously (Matsuki et al., 2006; Tomioka et al., 2006; Yoshida et al., 2012; Kunitomo et al., 2013). pDEST-
RGECO was a gift from Prof. Takeshi Ishihara (Kyushu University) and pDEST-RCaMP2 was kindly provided by Dr. Keiko Gengyo-Ando (Saitama University, Japan), Prof. Junichi Nakai (Saitama University, Japan), and Prof. Haruhiko Bito (The University of Tokyo). Transgenic strains were generated by microinjection of the following DNA mixtures to a hermaphrodite germline: $p G[g c y-7 p:: R C a M P 2](76.7 \mathrm{ng} / \mu \mathrm{l}) ; p G[\mathrm{lin}-44:: g f p]$

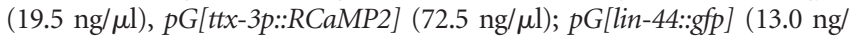
$\mu \mathrm{l}), p G[$ ins-1(short)p::RGECO] (94.2 ng/ $\mu \mathrm{l}) ; p G[$ lin-44:::gfp] $(26.1 \mathrm{ng} / \mu \mathrm{l})$, $p G[n p r-9 p:: R C a M P 2](56.9 \mathrm{ng} / \mu \mathrm{l}) ; p G[l i n-44:: g f p](18.4 \mathrm{ng} / \mu \mathrm{l})$. We found no obvious defects in the calcium response to salt concentration changes in these animals. Animals were cultivated on standard NGM until they were young adults and then were further cultivated overnight on NGM without or with $\mathrm{Na}^{+}(50 \mathrm{~mm})$. Then, an animal was immobilized in a microfluidic device (Chronis et al., 2007) with imaging solutions (containing $25 \mathrm{~mm}$ potassium phosphate, $\mathrm{pH} 6.0,1 \mathrm{~mm} \mathrm{CaCl}_{2}, 1 \mathrm{mM} \mathrm{MgSO}_{4}, 0.02 \%$ gelatin, 50 mM NaCl for worms cultivated without $\mathrm{Na}^{+}$and $100 \mathrm{mM} \mathrm{NaCl}$ for worms 
cultivated with $50 \mathrm{~mm} \mathrm{Na}^{+}$). Tetraethyl ammonium chloride (TEA, $20 \mathrm{~mm}$ ) or 3,4 diaminopyridine (3,4-DAP, $1 \mathrm{~mm}$ ) was added to the imaging solutions in the $\mathrm{K}^{+}$channel blocker experiments (Jospin et al., 2002; Jones et al., 2011). Optical stimulation and imaging were performed on a fluorescent microscope system (Olympus) described previously (Satoh et al., 2014) with modifications. Briefly, we used an upright microscope (BX51; Olympus) equipped with a halogen light source (U-LH100IR) and with a UplanApo $40 \times$ objective [numerical aperture (NA), 0.85], 530/50 nm band-path excitation filter, and DV2 photometrics (DV2-cube, T565 lpxr; Olympus), a motorized stage (HV-STU02-1; HawkVision), a CCD camera (GRAS03K2M-C; Point Gray Research), and a blue LED (470 nm, PE-100; CollLED) for worm observation and stimulation at 4 frames/s (exposure time: $50 \mathrm{~ms}$ ). In each experiment, frame recording for calcium imaging was initiated at a fixed time of 5 min after removal of animal from preassay cultivation plates. Individual animals were subjected to a single recording and replaced for each experiment. Regulated photostimulation was started after $20 \mathrm{~s}$ of recording and consisted of 20 cycles of $150 \mathrm{~ms}$ stimulations with $350 \mathrm{~ms}$ intervals ( $10 \mathrm{~s}$ in total). Only fluorescence images obtained during the $350 \mathrm{~ms}$ intervals were used for quantification. Average fluorescence intensity of the neurons (cell body for ASEL; dendrites for AIB, AIY, and AIA) was calculated from the region of interest (ROI), which was moved to track the object using the Track Objects function of MetaMorph software (Molecular Devices), followed by subtraction of the average intensity of the background region. The average fluorescence in a $10 \mathrm{~s}$ window (typically, time 11-20 s; 41-80 frame) was set as $F_{0}$ and the fluorescence intensity relative to $F_{0}$ $\left(F / F_{0}\right)$ was calculated for a series of images. For each figure, $F / F_{0}$ was averaged for all animals at each time point. The average $F / F_{0}$ in a $5 \mathrm{~s}$ window before stimulation (typically, time 3-7 s) was set as NS; the average $F / F_{0}$ in a $5 \mathrm{~s}$ window around the peak value during stimulation (typically, time 13-17 s; 16-10 s for AIB; see Fig. $4 b$ ) was set as DS. The $F / F_{0}$ change during stimulation equals DS subtracted by NS. We note that, in some experiments (see Figs. $3 e-g, 5 c, d$ ), the baselines of nonforward probability were different between conditions of ATR $(-)$ and ATR $(+)$. It appeared that the baselines of nonforward probability in AIYchannelrhodopsin-2 (ChR2) and AIA-ChR2 animals decreased and those in AIB-ChR2 increased under ATR $(+)$ conditions. This might be because ChR2 worms were exposed to weak light (ambient light) throughout the experiments, which may have reduced the baseline of nonforward probability in AIY-ChR2 and AIA-ChR2 animals and increased the baseline of nonforward probability in AIB-ChR2 animals.

Calcium imaging upon $\mathrm{Na}^{+}$stimulation. Calcium imaging was performed as described previously (Kunitomo et al., 2013) with some modifications. Strain JN611 (see details in Table 1) was used in this study. Briefly, animals were cultivated on standard NGM plates until they were young adults and were then further cultivated on NGM plates with or without $50 \mathrm{~mm} \mathrm{NaCl}$ overnight. One animal was then immobilized in a microfluidic device (described above) and $\mathrm{NaCl}$ concentration steps were delivered to its nose tip by switching the imaging solutions (solutions 1-4), as described below. Solution 1 contained $50 \mathrm{~mm} \mathrm{NaCl}$ and 50 mM NH $\mathrm{NH}_{4} \mathrm{Cl}$; solution 2 contained $60 \mathrm{~mm} \mathrm{NaCl}$ and $40 \mathrm{~mm} \mathrm{NH}_{4} \mathrm{Cl}$; solution 3 contained $50 \mathrm{~mm} \mathrm{NH}_{4} \mathrm{Ac}$; and solution 4 contained $40 \mathrm{~mm} \mathrm{NH}_{4} \mathrm{Ac}$. All solutions also contained $25 \mathrm{~mm}$ potassium phosphate, $\mathrm{pH} 6.0,1 \mathrm{~mm}$ $\mathrm{CaCl}_{2}, 1 \mathrm{mM} \mathrm{MgSO}_{4}$, and $0.02 \%$ gelatin and were supplemented with glycerol to adjust the osmolarity to $350 \mathrm{mOsm}$. TEA (20 mM) and 3,4DAP $(1 \mathrm{~mm})$ were added to the imaging solutions in $\mathrm{K}^{+}$channel blocker experiments (Jospin et al., 2002; Jones et al., 2011). Time-lapse images were acquired with a DMI-6000B microscope (Leica) equipped with an HCX-PL-APO $63 \times$ objective (NA, 1.40), N2.1 filter set (a combination of $515 \sim 560 \mathrm{~nm}$ band-path excitation filter and $580 \mathrm{~nm}$ dichromatic mirror; Leica), and the ImagEM EM-CCD camera (Hamamatsu) at 2 frames/s. The recording was started $5 \mathrm{~min}$ after fixation of animals in the microfluidic device. To shift $\mathrm{Na}^{+}$and $\mathrm{NH}_{4}{ }^{+}$concentrations, solution 1 was first used for the imaging buffer, switched to solution 2 after $25 \mathrm{~s}$ of recording, and then returned to solution 1 after $50 \mathrm{~s}$ recording. To switch $\mathrm{NH}_{4} \mathrm{Ac}$ concentrations, solution 3 was first used for the imaging buffer, switched to solution 4 after $25 \mathrm{~s}$ of recording, and then returned to solution 3 after $50 \mathrm{~s}$ recording. Fluorescence intensity in an ROI around the ASEL cell body was determined by correcting the position of ROI using Track Objects function of MetaMorph software (Molecular De- vices), followed by subtracting the average intensity of a background region. The average fluorescence in a $10 \mathrm{~s}$ window (typically, time 11-20 $\mathrm{s}, 21-40 \mathrm{f})$ was set as $F_{0}$ and the fluorescence intensity relative to $F_{0}\left(F / F_{0}\right)$ was calculated for a time series of images. For traces, a time series of $F / F_{0}$ values were determined from one animal per experiment and averaged for all animals at each time point.

Confocal imaging of ChR2 expression. Anesthetized hermaphrodite adults were imaged on a 5\% agar pad. Cultivation of the JN611 strain was the same as the above section ("Calcium imaging upon $\mathrm{Na}^{+}$stimulation”). Images of ChR2::Venus-expressing ASEL cell bodies (slice spacing of $0.5 \mu \mathrm{m}$ ) were acquired with a Leica SP 5 confocal microscope using a $63 \times / 1.30$ objective. The fluorescence measurements of worms cultivated with and without $\mathrm{Na}^{+}$were performed using the same parameter settings for excitation intensity, exposure time, and detector gain. For average ChR2::Venus fluorescence intensity of ASEL cell body, we determined an average pixel intensity of $Z$-stack images of ASEL cell bodies after subtraction of an average intensity of the background. For ChR2:: Venus fluorescence intensity of ASEL membrane, a line was drawn across the ASEL cell body of a $Z$-slice image, which was located at the center of the ASEL cell body. The peak intensity of the ASEL membrane was determined by subtracting the maximum fluorescence intensity on the line by the minimum fluorescence intensity on the line.

Statistical analysis. Statistical analyses were performed using GraphPad Prism 5 software. Two-tailed $t$ test was performed to compare the differences between two conditions of one strain (see Figs. $1 c, d, 5 f$ ) and between ATR $(+)$ and ATR $(-)$ (see Figs. $7 b, 8 b, c$ ). If there were more than two conditions, one-way ANOVA was performed first to determine whether there was significant difference among the conditions. In cases where there was a significant effect of conditions, one of the following post hoc tests was performed: Dunnett's test was performed to test the differences between wild-type and mutants or cell-ablation lines (see Figs. $1 c, 2,3 d)$; $t$ test with Bonferroni's correction was performed to test the differences between ATR $(+)$ and ATR $(-)$ (see Figs. $1 f, 3 d-g, 4 e, 6 b$ ) or test conditions (see Fig. $6 b$ ); Bonferroni's multiple-comparisons test (see Fig. $6 a, c, d$ ) or Tukey's test (see Fig. $7 c$ ) was performed to test many or all conditions in one experiment. Two-way ANOVA was used to test the effects of two factors, cultivation conditions, and strains (see Fig. 1c) or test conditions with the addition of ATR (see Figs. $1 f, 3 e-h, 5 a-e)$. In these cases, only ATR $(+)$ results were tested.

\section{Results}

\section{ASEL generates memory-dependent behaviors in $\mathrm{Na}^{+}$chemotaxis}

To test chemotaxis to $\mathrm{Na}^{+}$, we conducted a chemotaxis assay using an agar plate format with a $\mathrm{Na}^{+}$concentration gradient, but without a gradient for the counter-ion (Fig. 1b; see Materials and Methods for details). The chemotaxis assay revealed that, after cultivation in $\mathrm{Na}^{+}$-free conditions, worms showed no $\mathrm{Na}^{+}$ concentration preference but, after cultivation in the presence of $100 \mathrm{~mm} \mathrm{NaCl}$, worms showed positive $\mathrm{Na}^{+}$chemotaxis (i.e., they migrated to higher $\mathrm{Na}^{+}$concentrations; Fig. 1c). Detailed behavioral analysis revealed that, after cultivation with $100 \mathrm{mM} \mathrm{Na}^{+}$, worms showed a higher frequency of pirouette turns when $\mathrm{Na}^{+}$ concentration decreased, whereas the frequency of pirouettes was lower when $\mathrm{Na}^{+}$concentration increased, indicating that worms are more likely to engage in forward movement behavior when sensing increasing concentrations of $\mathrm{Na}^{+}$(Fig. 1d). Although ASEL is known to be the major $\mathrm{Na}^{+}$-sensing neuron, ASER also contributes to $\mathrm{Na}^{+}$chemotaxis to a lesser extent (Fig. 1 $a$; Ortiz et al., 2009). This minor influence on $\mathrm{Na}^{+}$chemotaxis complicates analysis of downstream neural circuits and, because of this, we decided to focus on ASEL's role in $\mathrm{Na}^{+}$chemotaxis by using optogenetics combined with behavioral assays and calcium imaging. Transgenic worms in which ChR2 was expressed only in ASEL were exposed to blue-light after preassay cultivation at different $\mathrm{Na}^{+}$concentrations and their behavioral response was 
a

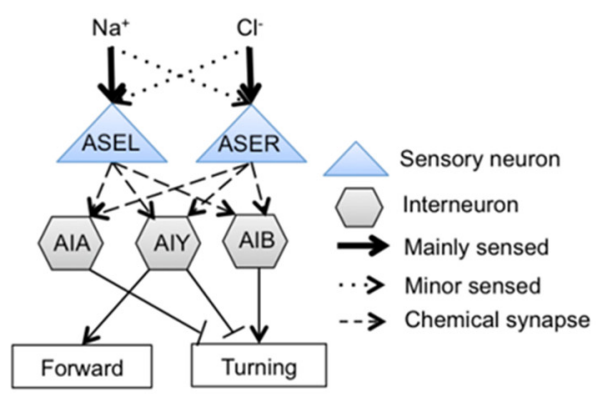

C

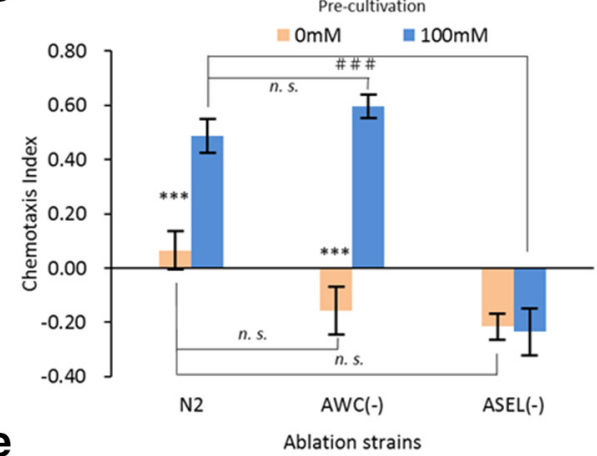

b

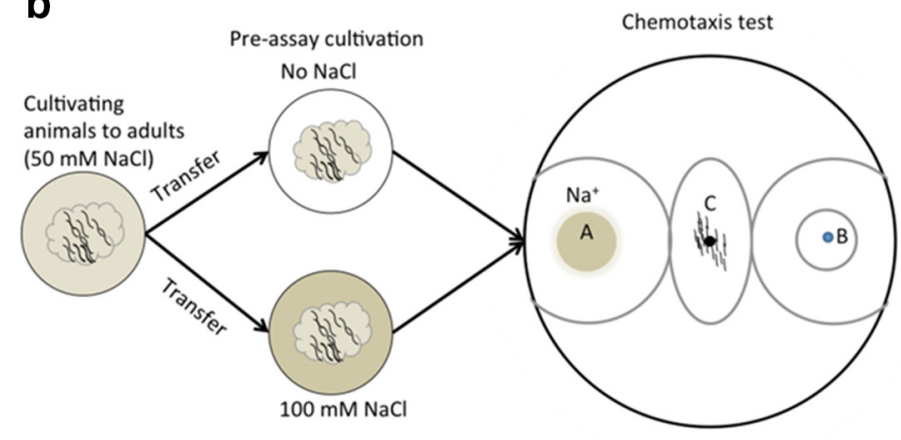

d

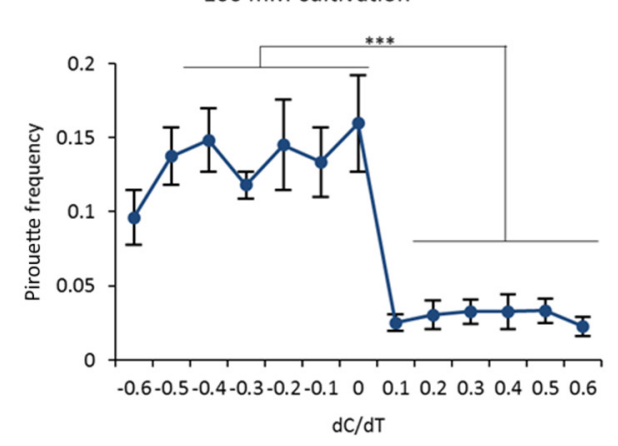

$50 \mathrm{mM}$ (cultivation)--> $50 \mathrm{mM}$ (test)

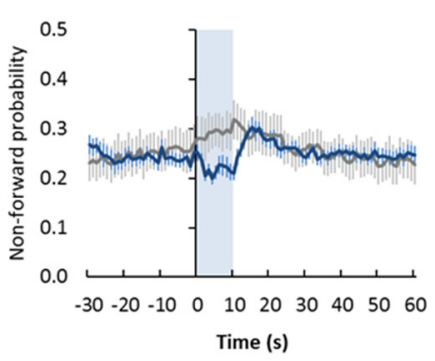

f

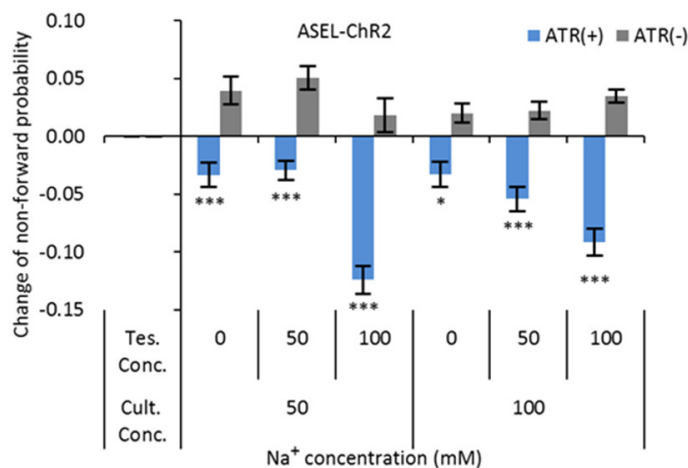

$100 \mathrm{mM}$ (cultivation)-->50 mM (test)

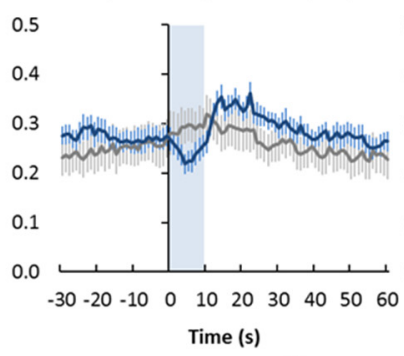

g

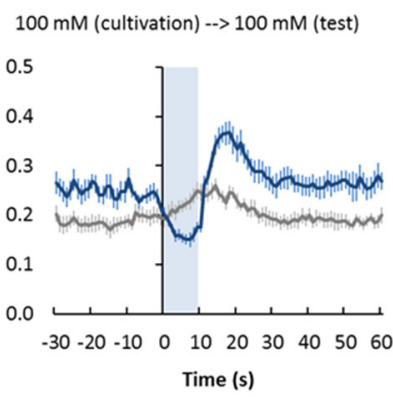

Time (s)

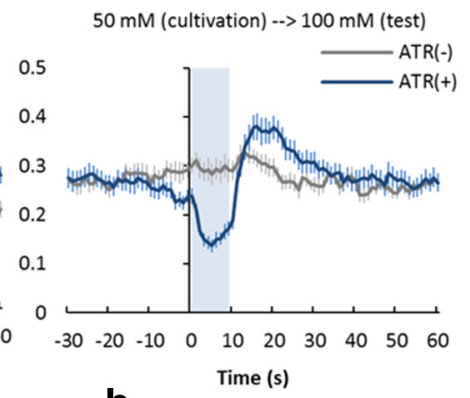

h

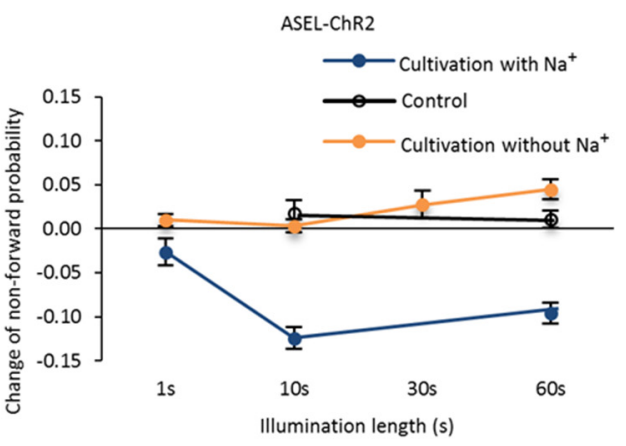

Cultivation with $\mathrm{Na}^{+}$

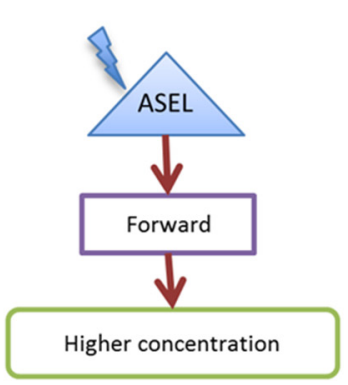

Figure 1. $\mathrm{Na}^{+}$chemotaxis assay and behavioral response to photoactivation of ASEL after cultivation with $\mathrm{Na}^{+}$. $\boldsymbol{a}$, Sensory specificity of ASE salt-sensing neurons (adapted from 0 rtiz et al., 2009) and its first-layer interneurons. $\boldsymbol{b}$, Procedure for the $\mathrm{Na}^{+}$chemotaxis assay. $\boldsymbol{c}, \mathrm{Na}^{+}$chemotaxis of wild-type N2, AWC-ablated, and ASEL-ablated strains after cultivation at 0 or $100 \mathrm{~mm} \mathrm{NaCl}$ (mean \pm $\mathrm{SEM}, n \geq 7)$. The cultivation concentrations have a significant effect on chemotaxis index $\left(F_{(2,34)}=13.08, p<0.0001\right)$; the neuronal cell-ablated strains have significant influence in chemotaxis $\operatorname{index}\left(F_{(1,34)}=22.80, p<0.0001\right)$, the interaction between neuronal cell-ablated strains and cultivation concentrations is considered significant $\left(F_{(2,34)}=11.92, p=0.0001 ;\right.$ two-way ANOVA). $\boldsymbol{d}$, Pirouette frequency of worms in chemotaxis assay after cultivation with $100 \mathrm{~mm} \mathrm{Na}^{+}$(mean $\pm \mathrm{SEM}, n=13$ ). Difference between decreased $\mathrm{Na}^{+}$concentrations and increased $\mathrm{Na}^{+}$ concentrations: ${ }^{* * *} p<0.001, t$ test. $\boldsymbol{e}$, Nonforward probability (see Results and Materials and Methods for definition) evoked by optical stimulation of ASEL in different cultivation and test Na ${ }^{+}$ concentrations (mean $\pm S E M, n \geq 12$ ). Animals were cultivated at the indicated concentrations of $\mathrm{Na}^{+}$(preassay cultivation) and illuminated by blue light (blue vertical lines) on agar plates with different $\mathrm{Na}^{+}$test concentrations. $f$, Change of nonforward probability of worms during ASEL photostimulation in different cultivation and test concentrations (see Materials and Methods) (mean \pm SEM, $n \geq 12)$. Difference between ATR $(+)$ and ATR $(-): F_{(11,150)}=29.936, p<0.0001 ; k=6,{ }^{*} k p<0.05,{ }^{* * *} k p<0.001$, one-way ANOVA followed by $t$ test with Bonferroni's correction. For the $\operatorname{ATR}(+)$ conditions, the test concentrations have significant effect on behavioral response $\left(F_{(2,81)}=30.53, p<0.0001\right)$, the cultivation concentrations have a nonsignificant effect on behavioral response $\left(F_{(1,81)}=0.03, p=0.8733\right)$, and the interaction between test concentrations and cultivation concentrations is considered significant $\left(F_{(2,81)}=3.35, p=0.0401 ;\right.$ two-way ANOVA). $\boldsymbol{g}$, Change of nonforward probability upon ASEL's activation for different time lengths (mean $\pm S E M, n \geq 6$ ). $\boldsymbol{h}$, Model of ASEL that generates forward locomotion after cultivation with Na ${ }^{+}$. 
a

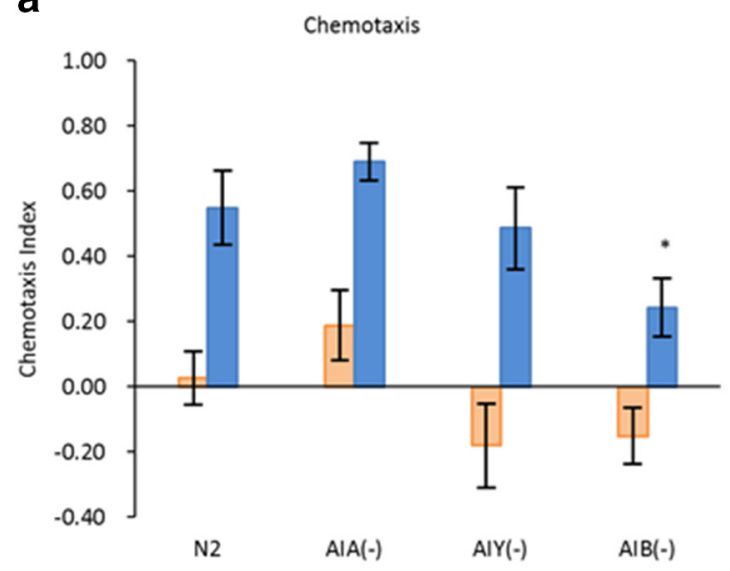

C

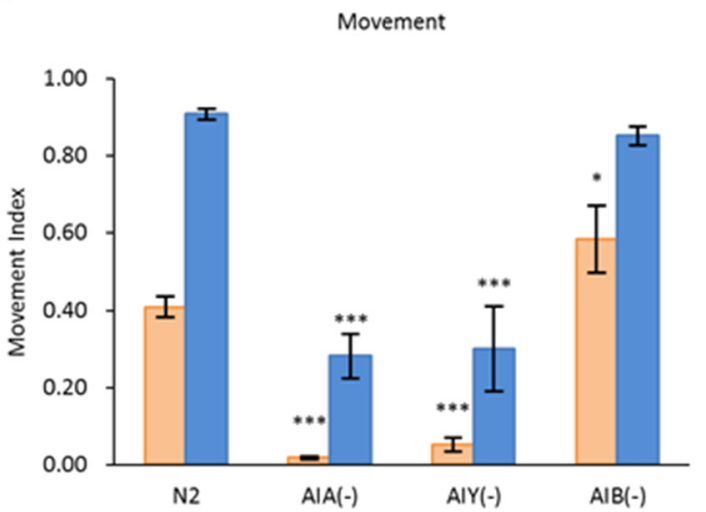

b

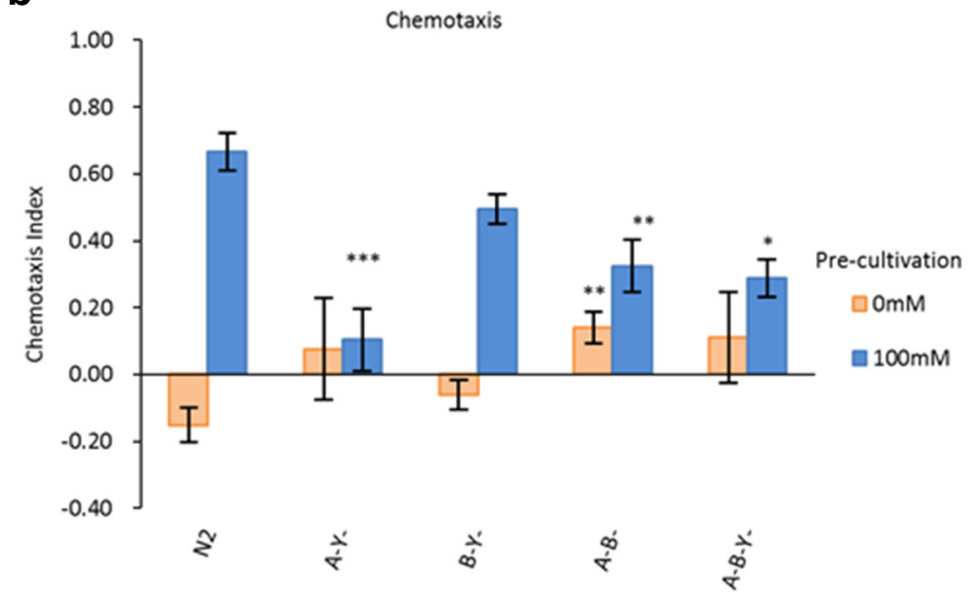

Movement

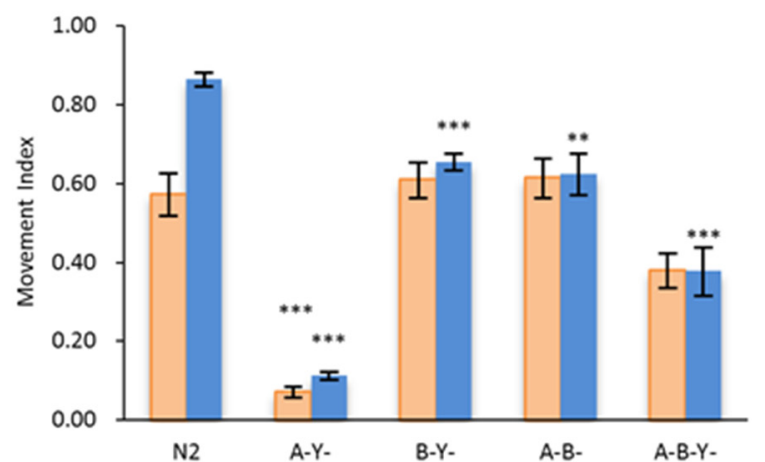

Figure 2. $\mathrm{Na}^{+}$chemotaxis of interneuron-ablated animals. $\boldsymbol{a}, \boldsymbol{b}$, Na chemotaxis of transgenic lines expressing mouse caspase in each class of interneurons or combinations of them (mean \pm SEM, $n \geq 4)$. Difference between mutants and wild-type: $\boldsymbol{a}, F_{(3,18)}=5.744, p=0.0061 ; \boldsymbol{b}, F_{(4,30)}=8.411, p<0.0001,{ }^{*} p<0.05,{ }^{* *} p<0.01,{ }^{* * *} p<0.001$, one-way ANOVA followed by Dunnett's test. AIA (-) is the AIA-ablated strain, AIB (-) is the AIB-ablated strain; AIY (-) is the AIY-ablated strain; A-Y - is the AIA-and AIY-ablated strain; A-B- is the AIA- and AIB-ablated strain; $B-Y-$ is the AIB- and AIY-ablated strain; and A-B-Y - is the AIA-, AIB-, and AIY-ablated strain. $\boldsymbol{c}$, $\boldsymbol{d}$, Movement index of animals in the same assay as $\boldsymbol{a}$ and $\boldsymbol{b}$. Difference between mutants and wild-type: $F_{(3,20)}=53.59, p<0.0001$ (0 mm cultivation), $F_{(3,18)}=48.33, p<0.0001$ (100 mm cultivation) $(c) ; F_{(4,28)}=16.09, p<0.0001\left(0 \mathrm{~mm}\right.$ cultivation), $F_{(4,30)}=56.02, p<0.0001(100$ mm cultivation) (d). ${ }^{*} p<0.05,{ }^{* * *} p<0.001$, one-way ANOVA followed by Dunnett's test).

quantified by using the worm-tracking system. Because ASEL is activated by an increase in $\mathrm{Na}^{+}$concentration, optogenetic activation of ASEL mimics an increase of $\mathrm{Na}^{+}$concentrations. We evaluated the behavioral response by quantifying the nonforward probability, which was calculated as the ratio of animals that were performing pirouettes, sharp turns, or pauses at each time point. In other words, nonforward probability $=1-$ the rate of forward locomotion. When worms were cultivated with $\mathrm{Na}^{+}$and tested on plates at any $\mathrm{Na}^{+}$concentration (including absence of $\mathrm{Na}^{+}$), the nonforward probability decreased (forward locomotion was stimulated) during blue-light stimulation of ASEL and increased after blue-light illumination was turned off (Fig. 1e,f). These results are similar to the previous observation of behavioral responses to step concentration changes of $\mathrm{NaCl}$ (Miller et al., 2005), consistent with the above results on pirouette frequency (Fig. 1d), and can generate chemotaxis toward a higher salt concentration through the klinokinesis mechanism. These results were consistent with the observation that, during the $\mathrm{Na}^{+}$chemotaxis assay (Fig. $1 b$ ), worms that were cultivated with $\mathrm{Na}^{+}$ migrated to a higher concentration (Fig. 1h). Extending the stimulation time caused no change in worms' behavioral patterns (Fig. 1g), which was also the case in earlier reports on photoactivation of AIY (Li et al., 2014) and AWA (Larsch et al., 2015). After cultivation at 50 or $100 \mathrm{mM} \mathrm{Na}^{+}$, worms showed larger forward locomotion responses upon ASEL photoactivation on test plates with $100 \mathrm{mM} \mathrm{Na}^{+}$compared with those with 50 or $0 \mathrm{mM} \mathrm{Na}^{+}$ (Fig. 1f).

\section{AIB is required for $\mathrm{Na}^{+}$chemotaxis after cultivation with $\mathrm{Na}^{+}$}

AIB, AIY, and AIA are the first-layer interneurons that receive synaptic inputs from ASEL (White et al., 1986; Fig. 1a), but the role of each neuron in $\mathrm{Na}^{+}$chemotaxis had not yet been examined. AIB-ablated animals showed significantly reduced $\mathrm{Na}^{+}$ chemotaxis when worms were cultivated at $100 \mathrm{mM} \mathrm{Na}^{+}$(Fig. $2 a$ ), suggesting that AIB is required for transmission of sensory signals from ASEL. In the previous report, $\mathrm{NaCl}$ chemotaxis was affected minimally in AIB-ablated animals, whereas klinokinesis was reduced significantly (Kunitomo et al., 2013). Conversely, although AIA- or AIY-ablated animals showed reduced locomotion activity (Fig. $2 c$ ), their chemotaxis to $\mathrm{Na}^{+}$was not affected severely (Fig. 2a). AIA/AIY double-ablated animals showed a defect in $\mathrm{Na}^{+}$chemotaxis (Fig. 2b), suggesting that AIA and AIY may be involved in ASEL-induced chemotaxis. It is also possible, however, that the observed $\mathrm{Na}^{+}$chemotaxis defect in the AIY/ AIA double mutant was caused by reduced locomotion ability (Fig. 2c,d). 


\begin{abstract}
AIB, AIY, and AIA are all required for stimulation of forward locomotion by ASEL after cultivation with $\mathrm{Na}^{+}$

AIB is activated upon down-stepping of the $\mathrm{NaCl}$ concentration through the off-response neuron ASER (Oda et al., 2011; Kunitomo et al., 2013). Because AIB was required for $\mathrm{Na}^{+}$chemotaxis, we investigated whether AIB is required for the behavioral response generated by ASEL activation. Behavioral response upon stimulation of ASEL was diminished significantly in AIB-ablated animals (Fig. $3 a, d$ ). It was therefore suggested that AIB was required for stimulation of forward locomotion upon activation of ASEL by ChR2. AIY is an important interneuron for controlling multiple behaviors and is involved in regulating reversal and gradual turning (Kocabas et al., 2012; Satoh et al., 2014). Behavioral responses after ASEL photoactivation were completely eliminated in AIY-ablated animals: there was no decrease of nonforward probability during ASEL photoactivation or increase of nonforward probability after termination of ASEL stimulation (Fig. 3b,d). Furthermore, similar to ASEL, AIA is reportedly activated in response to up-steps of $\mathrm{NaCl}$ concentrations, implying that AIA receives excitatory inputs from ASEL either directly or indirectly (Oda et al., 2011). We found that the change of nonforward probability was significantly smaller or eliminated when ASEL was stimulated by ChR2 in AIA-ablated animals (Fig. $3 c, d$ ), indicating that AIA is required for the behavioral response to ASEL activation. Therefore, ASEL requires all first-layer interneurons, AIB, AIY, and AIA, for generating behavioral responses.
\end{abstract}

\section{AIB promotes turning behavior, whereas AIY and AIA promote forward locomotion}

Interneurons AIB, AIY, and AIA have synapses with many of the sensory neurons, including ASER, AWC, and ASEL, all of which are implicated in chemotaxis to chemical cues (Chalasani et al., 2007, 2010; Kunitomo et al., 2013; Satoh et al., 2014). AIB showed increased calcium levels upon odor removal (Chalasani et al., 2007) and decreased $\mathrm{NaCl}$ concentration (Kunitomo et al., 2013) and stimulated turning behavior (Fig. 1a). Behavioral assays showed that the nonforward probability increased during AIB stimulation by ChR2 in many conditions of $\mathrm{Na}^{+}$concentrations (Fig. $3 e$ ) and the magnitude of the response was not related to test concentrations or cultivation concentrations. In contrast, AIY was reported to show increased calcium level upon odor addition and decreased calcium level upon odor removal (Chalasani et al., 2007) and AIY activation promoted forward locomotion and inhibited turning (Fig. 1a; Li et al., 2014). For stimulation of AIY, we used two strains that express ChR2 in AIY (strain \#1 and \#2; see Materials and Methods). When AIY was stimulated by ChR2, the nonforward probability decreased in both strains during AIY stimulation and increased after termination of AIY stimulation in most cultivation conditions (Fig. 3g,h). It was also reported that AIA is activated by the addition of odor (Chalasani et al., 2010) and that activated AIA inhibits turning behavior (Fig. 1a; Larsch et al., 2015). Our results revealed that, when AIA was stimulated by ChR2, the behavioral response was similar to that of AIY stimulation: the nonforward probability decreased during stimulation of AIA by ChR2 and increased after termination of AIA stimulation in most conditions of cultivation $\mathrm{Na}^{+}$concentrations (Fig. 3f), Therefore, behavioral response to ASEL stimulation was similar to AIY stimulation or AIA stimulation but opposite to AIB stimulation, suggesting a positive relationship between ASEL and AIY/AIA but a negative relationship between ASEL and AIB.

\section{ASEL inhibits AIB and activates AIY and AIA after cultivation} with $\mathrm{Na}^{+}$

We used a combination of photostimulation with ChR2 and calcium monitoring with RCaMP2 (Inoue et al., 2015) or RGECO (only for AIA) (Zhao et al., 2011) to observe directly the response of each neuron to activation of ASEL (Fig. $4 a-e$; see Materials and Methods for details of experimental setup). We first confirmed that the calcium content of ASEL was increased upon ASEL stimulation (Fig. 4a,e). The calcium level of AIB was decreased significantly upon ASEL photostimulation, indicating that AIB was inhibited by ASEL (Fig. $4 b, e$ ). AIY's calcium content was increased during photoactivation of ASEL (Fig. $4 d, e$ ), revealing that AIY was activated by ASEL. In addition, some variation of calcium levels in AIB and AIY were observed before photostimulation of ASEL, possibly because of the spontaneously activating characteristics of these neurons (Chalasani et al., 2007; Gordus et al., 2015). Similar to AIY, AIA's calcium content was increased upon ASEL stimulation, indicating that AIA was also activated by ASEL (Fig. $4 c, e)$. Even under cultivation conditions without ATR, blue light stimulation decreased calcium levels of AIY and ASEL. Although we used strains with the lite-1 background for optogenetic experiments, lite-1 mutations were reported to diminish but not completely eliminate worms' response to blue light stimulation, suggesting that intrinsic response to blue light remains in these strains to some extent (Edwards et al., 2008; Ward et al., 2008; Li et al., 2014; Liu et al., 2010). Therefore, judging from the difference between ATR $(+)$ and ATR (-), all three first-layer interneurons respond to ASEL photoactivation: AIB was inhibited by ASEL, which is expected to inhibit turning behavior, whereas AIY and AIA were activated by ASEL to possibly promote forward locomotion; therefore, all three interneurons may contribute to driving worms to higher $\mathrm{Na}^{+}$concentrations (Fig. $4 f$ ). AIA and AIY, together with AIB, mediate ASEL-generated behavioral response after cultivation with $\mathrm{Na}^{+}$.

\section{Cellular basis of behavioral plasticity caused by cultivation with or without $\mathrm{Na}^{+}$}

In the chemotaxis assay, we observed that, when worms were cultivated in $\mathrm{Na}^{+}$-free conditions, they had no $\mathrm{Na}^{+}$concentration preference (Fig. 1c). This is not due to general deficits in sensory or motor functions because the same cultivation conditions do not affect chemotaxis to odorants (Kunitomo et al., 2013). To determine the underlying mechanism for modulation, we tested the behavioral response to ASEL stimulation after $\mathrm{Na}^{+}$-free cultivation. When worms were cultivated in $\mathrm{Na}^{+}$-free conditions, they showed no behavioral response to ASEL photostimulation in the presence of $\mathrm{Na}^{+}$ (Fig. 5a). We tested which ion, $\mathrm{Na}^{+}$or $\mathrm{Cl}^{-}$, changes the behavioral response to ASEL stimulation when present during preassay cultivation. We used $\mathrm{NaAc}$ instead of $\mathrm{NaCl}$ as a salt included in either the cultivation or test plates. As a result, worms displayed similar behavioral responses upon ASEL activation after $\mathrm{NaCl}$ or NaAc cultivation: increased forward movement during stimulation. Likewise, replacing $\mathrm{NaCl}$ with $\mathrm{NaAc}$ in test plates did not cause a significant difference (Fig. $6 a, b$ ), indicating that $\mathrm{Na}^{+}$is responsible for the plasticity in the behavioral response to ASEL stimulation.

The next question was whether $\mathrm{Na}^{+}$is sensed directly by ASEL during preassay cultivation to generate behavioral plasticity. To answer this, we made use of the $d y f-11$ mutant, which has deformed cilia and therefore cannot sense water-soluble chemicals (Kunitomo and Iino, 2008). When worms were cultivated with $\mathrm{Na}^{+}$, reduced turning behavior was no longer observed in $d y f-11$ 

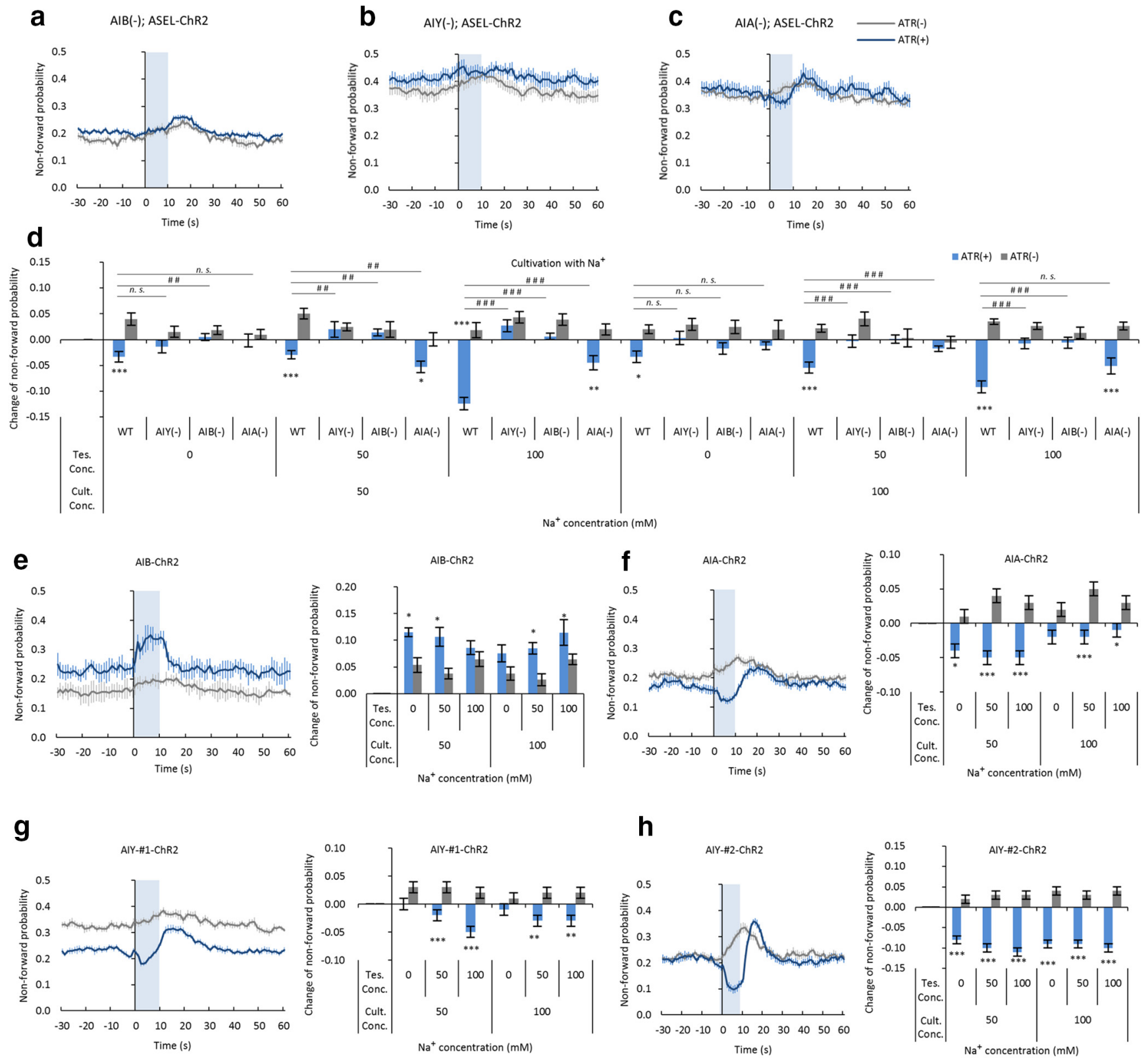

Figure 3. Behavioral response to activation of ASEL after cultivation with $\mathrm{Na}^{+}$. $\boldsymbol{a}-\boldsymbol{c}$, Behavioral response upon ASEL photoactivation of AIB-ablated animals $(\boldsymbol{a})$, AIY-ablated animals $(\boldsymbol{b})$, and AlA-ablated animals (c) when worms were transferred from $50 \mathrm{~mm} \mathrm{Na}^{+}$cultivation to $100 \mathrm{~mm}$ test concentration (mean $\pm S E M, n \geq 12$ ). $\boldsymbol{d}$, Change of nonforward probability in interneuronablated animals upon ASEL photostimulation in different cultivation and test concentrations (mean \pm SEM, $n \geq 12)$. Difference between ATR $(-)$ and ATR $(+): F_{(47,550)}=10.95, p<0.0001, k=$ $24,{ }^{*} k p<0.05,{ }^{* *} k p<0.01,{ }^{* * *} k p<0.001$, one-way ANOVA followed by $t$ test with Bonferroni's correction. Difference of ATR $(+)$ results between wild-type and ablation lines: \#\#p $<0.01$, $\# \# \#<0.001$, n.s., no significant difference, one-way ANOVA followed by Dunnett's test. $\boldsymbol{e}-\boldsymbol{h}$, Left, Behavioral response when AIB (e), AIA (f), or AIY ( $\boldsymbol{g}, \boldsymbol{h})$ was stimulated by ChR2 after worms were transferred from $50 \mathrm{~mm} \mathrm{Na}^{+}$cultivation to $100 \mathrm{~mm}(50 \mathrm{~mm}$ for $\boldsymbol{e}$ ) test concentration (mean $\pm \mathrm{SEM}, n \geq 12)$. Right, Change of nonforward probability upon photoactivation of AIB (e), AIA (f), AIY in the strain \#1 (g), or AlY in strain \#2 (h) in different cultivation and test concentrations (mean \pm SEM, $n \geq 12$ ). Difference between ATR $(-)$ and ATR $(+): F_{(11,135)}=5.046, p<0.0001(\boldsymbol{e})$; $F_{(11,141)}=14.35, p<0.0001(\boldsymbol{f}) ; F_{(11,133)}=9.365, p<0.0001(\boldsymbol{g}) ; F_{(11,131)}=9.810, p<0.0001(\boldsymbol{h}) . k=6,{ }^{*} k p<0.05,{ }^{* *} k p<0.01, * * * k p<0.001$, one-way ANOVA followed by $t$ test with Bonferroni's correction. For ATR $(+)$ conditions of AIB-ChR2 $(e)$, neither test concentrations $\left(F_{(2,68)}=0.08, p=0.9194\right)$ nor cultivation concentrations $\left(F_{(1,68)}=0.67, p=0.4146\right)$ had a significant effect on behavioral response to AIB photostimulation, nor was there any significant interaction between the two factors $\left(F_{(2,68)}=2.84, p=0.0654\right.$, two-way ANOVA). For ATR ( + ) conditions of AIA-ChR2 $(f)$, the cultivation concentrations had a significant effect on behavioral response to AIA phtostimulation $\left(F_{(1,65)}=14.41, p=0.0003\right)$, whereas the test concentration had no significant effect $\left(F_{(2,65)}=0.36, p=0.7002\right)$ and there was no significant interaction between the two factors $\left(F_{(2,65)}=0.33, p=0.7216\right.$, two-way ANOVA). For ATR $(+)$ conditions of AIY-\#1-ChR2 $(g)$, the test concentration had a significant effect on behavioral response to AlY photostimulation $\left(F_{(2,67)}=7.64, p=0.0010\right)$, whereas the cultivation concentration had no significant effect $\left(F_{(1,67)}=\right.$ $0.08, p=0.7830)$ and there was no significant interaction between the two factors $\left(F_{(2,67)}=1.02, p=0.3660\right.$, two-way ANOVA). For ATR $(+)$ conditions of AIY-\#2-ChR2 (h), neither test concentrations $\left(F_{(2,67)}=1.27, p=0.2872\right)$ nor cultivation concentrations $\left(F_{(1,67)}=0.00, p=0.9508\right)$ had a significant effect on behavioral response to AIB photostimulation, nor was there any significant interaction between the two factors $\left(F_{(2,67)}=0.45, p=0.6364\right.$, two-way ANOVA).

mutants when ASEL was stimulated by ChR2 and this defect was rescued by $d y f-11$ expression only in ASEL (Fig. 6c). When worms were cultivated in $\mathrm{Na}^{+}$-free conditions, they showed increase of nonforward probability upon ASEL photoactivation in the $d y f-11$ mutant and this response was suppressed by $d y f-11$ expression in ASEL neurons (Fig. 6d). These results indicated that ASEL alone could generate $\mathrm{Na}^{+}$-dependent plasticity (behavioral response only after cultivation with $\mathrm{Na}^{+}$). 
a

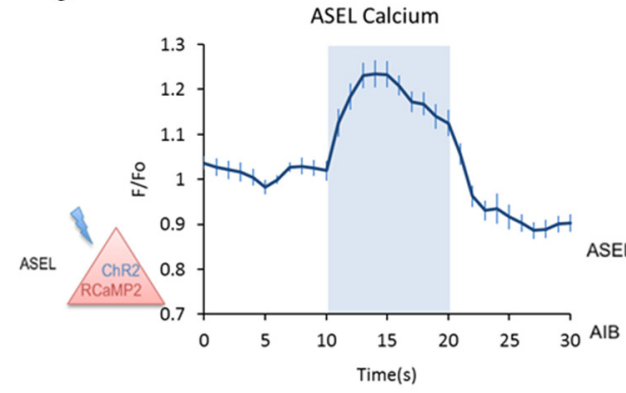

d

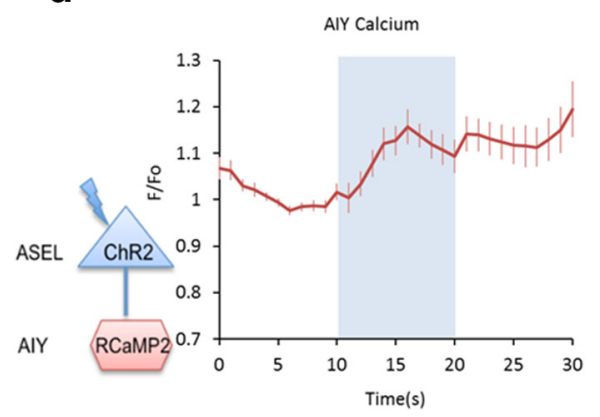

b

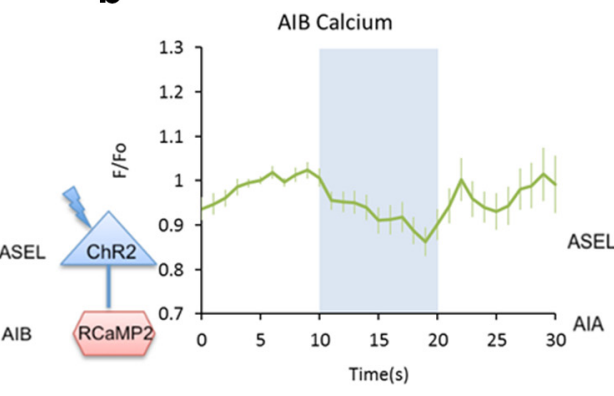

e

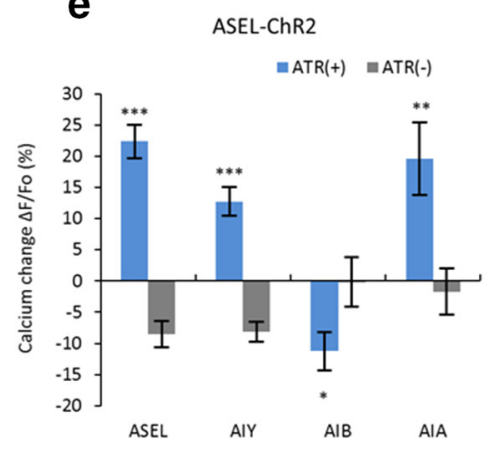

C

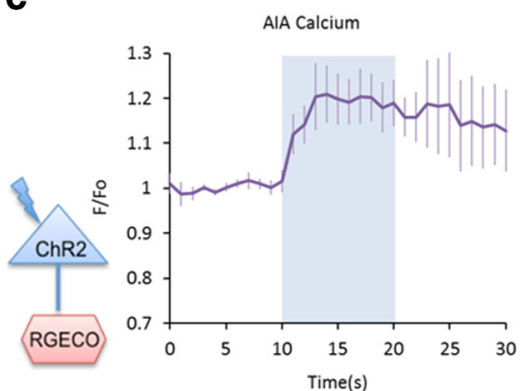

f

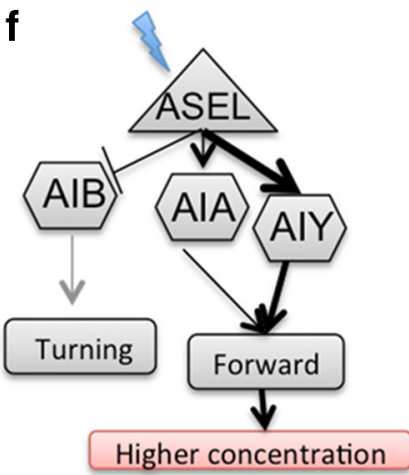

Figure 4. Neural circuit for behavioral responses to ASEL photostimulation after cultivation with $\mathrm{Na}^{+}$. $\boldsymbol{a}$, Left, Coexpression of ChR2 and RCaMP2 in ASEL. Right, Calcium response of ASEL upon ASEL photostimulation when worms were transferred from $50 \mathrm{~mm} \mathrm{Na}^{+}$cultivation to $100 \mathrm{~mm}$ imaging buffer (see Material and Methods) (optical stimulation strength was 0.5 $\mathrm{mW} / \mathrm{mm}^{2}$, mean \pm SEM, $n \geq 18$ ). $\boldsymbol{b}$, Left, Schematic of AIB expression of RCaMP2 in transgenic worms in which ChR2 was expressed in ASEL. Right, Calcium response of AIB upon ASEL photostimulation when worms were transferred from $50 \mathrm{~mm} \mathrm{Na}^{+}$cultivation to $100 \mathrm{~mm}$ imaging buffer (see Material and Methods). Optical stimulation strength was $0.5 \mathrm{~mW} / \mathrm{mm}^{2}$, mean \pm SEM, $n \geq 19$. c, Left, Schematic of AIA expression of RGECO in transgenic worms in which ChR2 was expressed in ASEL. Right, AIA calcium response during ASEL stimulation by ChR2 when worms were transferred from $50 \mathrm{~mm} \mathrm{Na}^{+}$cultivation to $100 \mathrm{~mm}$ imaging buffer. Optical stimulation strength was $0.5 \mathrm{~mW} / \mathrm{mm}^{2}$, mean \pm SEM, $n \geq 11$. d, Left, Schematic of AIY expression of RCaMP2 in transgenic worms in which ChR2 was expressed in ASEL. Right, AIY calcium response when ASEL was stimulated by ChR2 when worms were transferred from $50 \mathrm{~mm} \mathrm{Na}^{+}$cultivation to $100 \mathrm{~mm}$ imaging buffer. Optical stimulation strength was $0.4 \mathrm{~mW} / \mathrm{mm}^{2}$, mean $\pm \mathrm{SEM}, n \geq 20$. , Calcium response change of neurons ( $\boldsymbol{a}-\boldsymbol{d}$ ) during stimulation of ASEL. Difference between ATR $(-)$ and ATR $(+): F_{(7,137)}=17.84, p<0.0001, k=4,{ }^{*} k p<0.05,{ }^{* *} k p<0.01,{ }^{* * *} k p<0.001$, one-way ANOVA followed by $t$ test with Bonferroni's correction. $f$, Speculated neural circuit downstream of ASEL after cultivation with $\mathrm{Na}^{+}$.

Conversely, when AIB, AIY, or AIA was stimulated by ChR2, wild-type worms cultivated in $\mathrm{Na}^{+}$-free conditions showed similar responses to those cultivated with $\mathrm{Na}^{+}$(Figs. $3 e-h, 5 b-e)$. This implied that the difference in the behavioral responses after $\mathrm{Na}^{+}$-containing and $\mathrm{Na}^{+}$-free cultivation conditions was attributed to neuronal responses upstream of firstlayer interneurons, possibly in ASEL. In fact, ASEL showed no calcium response upon ASEL photostimulation after $\mathrm{Na}^{+}$-free cultivation (Fig. $5 f$ ). This is likely the reason that there was no behavioral response to ASEL stimulation after $\mathrm{Na}^{+}$-free cultivation and no $\mathrm{Na}^{+}$concentration preference after cultivation in $\mathrm{Na}^{+}$-free conditions (Fig. $5 g$ ).

\section{Inhibition of $\mathrm{K}^{+}$channel rescued ASEL's response after cultivation without $\mathrm{Na}^{+}$}

Due to the unexpected lack of calcium response of ASEL after photoactivation, we investigated whether ChR2 was still present in the ASEL neuron after cultivation without $\mathrm{Na}^{+}$by observing ChR2 expression under a confocal microscope. We found that ChR2 tagged with Venus was still present and localized to the cell membrane of ASEL after cultivation without $\mathrm{Na}^{+}$(Fig. 7a) and the fluorescence intensity of ChR2::Venus in the ASEL cell body and membrane was not different from that in animals that were cultivated with $\mathrm{Na}^{+}$(Fig. 7b). This result revealed that expression and localization of ChR2 in ASEL was not affected by the presence or absence of $\mathrm{Na}^{+}$in cultivation conditions.

Next, we investigated ASEL's calcium responses to $\mathrm{Na}^{+}$concentration changes after cultivation without $\mathrm{Na}^{+}$. ASEL showed no calcium response when $\mathrm{Na}^{+}$concentration was changed from 50 to $60 \mathrm{~mm}$ after cultivation without $\mathrm{Na}^{+}$; whereas, after cultivation with $\mathrm{Na}^{+}$, the calcium level of ASEL increased when the $\mathrm{Na}^{+}$concentration was changed from 50 to $60 \mathrm{~mm}$ (Fig. $7 c, e$ ). Because the concentration of the counter ion, $\mathrm{NH}_{4}{ }^{+}$, also changed upon $\mathrm{Na}^{+}$concentration change during imaging assays, we tested the effect of $\mathrm{NH}_{4}{ }^{+}$concentration changes on ASEL's calcium response. Consistent with the previous report showing that a $10 \mathrm{~mm}$ concentration change of $\mathrm{NH}_{4}{ }^{+}$did not cause a calcium response in ASEL (Suzuki et al., 2008), ASEL showed no response to a $10 \mathrm{~mm}$ down-step of $\mathrm{NH}_{4}{ }^{+}$after cultivation with or without $\mathrm{Na}^{+}$(Fig. 7 c).

The above observations suggested that, after cultivation without $\mathrm{Na}^{+}$, ASEL was not activated in response to cation influx by either ChR2 or a sensory input. This could be due to activation of a shunting function and likely candidates for this function are $\mathrm{K}^{+}$channels (Daoudal and Debanne, 2003). We therefore used $\mathrm{K}^{+}$channel blockers to determine whether any of them could rescue ASEL's response to $\mathrm{Na}^{+}$concentration changes after cultivation without $\mathrm{Na}^{+}$. The results showed that ASEL's calcium level was increased in response to $10 \mathrm{~mm}$ $\mathrm{Na}^{+}$up-step (Fig. $7 c$ ) or ASEL photostimulation (Fig. $7 d$ ) even after cultivation without $\mathrm{Na}^{+}$when the $\mathrm{K}^{+}$channel blockers TEA and 3,4-DAP were added to the perfusion buffer. Therefore, $\mathrm{K}^{+}$channels play a role in making ASEL resistant to excitatory stimuli after cultivation without $\mathrm{Na}^{+}$, which may be mitigated by $\mathrm{K}^{+}$channel blockers to allow ASEL depolariza- 

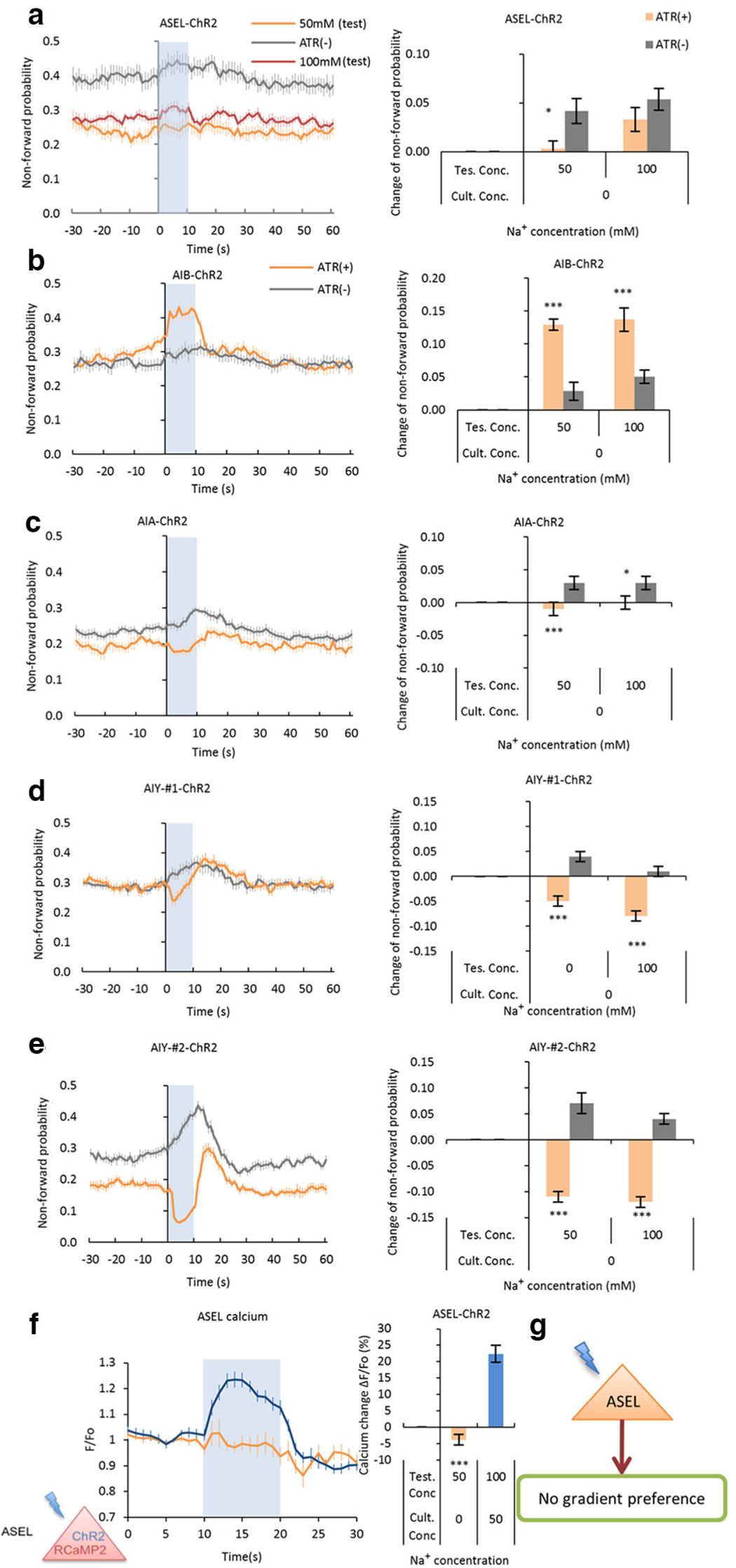

Figure 5. Behavioral response to photoactivation of ASEL after cultivation without $\mathrm{Na}^{+}$. $\boldsymbol{a}$, Behavioral response (left) and change of nonforward probability (right) to optical stimulation of ASEL when worms were transferred from $\mathrm{Na}^{+}$-free cultivation to $50 \mathrm{~mm} \mathrm{Na}^{+}$[in the left figure, gray line is ATR $(-)$and orange line is ATR $(+)$and red line is ATR $(+)$) at $100 \mathrm{~mm} \mathrm{Na}^{+}$(mean \pm SEM $n \geq 12$ ). Difference between $\operatorname{ATR}(-)$ and $\operatorname{ATR}(+): F_{(3,47)}=3.31, p=0.0278, k=2,{ }^{*} k p<0.05$, one-way tion by up-steps of $\mathrm{Na}^{+}$concentrations or photostimulation (Fig. 7e).

eat-4 and egl-30 in ASEL are involved in ASEL-triggered behavioral response

eat-4, which encodes a vesicular glutamate transporter, is necessary for glutamatergic transmission in C. elegans (Lee et al., 1999; Rand et al., 2000; Lee et al., 2008). eat-4 is also expressed in ASE neurons (SerranoSaiz et al., 2013), which implies that ASE neurons release glutamate onto downstream interneurons. An eat-4 mutation eliminated the behavioral response upon ASEL activation after cultivation with $\mathrm{Na}^{+}$. Moreover, cell-specific knockdown of eat- 4 in ASEL by RNA interference caused smaller behavioral responses than those seen in wild-type animals during ASEL stimulation (Fig. 8a), suggesting that glutamate is used as a neurotransmitter in ASEL for the behavioral responses.

egl-30, which encodes an ortholog of the $\alpha$ subunit of heterotrimetric G-protein Gq, regulates locomotory movements positively (Brundage et al., 1996; Lackner et al., 1999; Adachi et al., 2010). The Gq/DAG/PKC pathway modulates $\mathrm{NaCl}$ chemotaxis and counteracts phophatidylinositol 3-kinase signaling (Tomioka et al., 2006; Adachi et al., 2010; Kunitomo et al., 2013). Conversely, manipulation of the $\mathrm{Gq}$ signaling pathway in ASEL has only a marginal effect on chemotaxis to $\mathrm{NaCl}$ (Adachi et al., 2010). We therefore investigated whether the Gq signaling pathway regulates ASEL-dependent chemotaxis. egl-30(pe914), a gain-offunction mutation, is characterized by hyperactive locomotion (Tomioka et al., 2006; Adachi et al., 2010). In the transgenic

ANOVA followed by $t$ test with Bonferroni's correction. $\boldsymbol{b}-\boldsymbol{e}$ Left, Behavioral response upon photoactivation of $\operatorname{AIB}(\boldsymbol{b})$, AIA (c), or AIY\#1 (d), AIY\#2 (d) when worms were transferred to 50 $\mathrm{mM} \mathrm{Na}{ }^{+}$test concentration after $\mathrm{Na}^{+}$-free cultivation (mean \pm SEM, $n \geq 11$ ). Right, Change of nonforward probability during stimulation of AIB (b), AIA (c), AIY (in the \#1 strain) (d), AIY (in the \#2 strain) (e), or when worms were transferred to different $\mathrm{Na}^{+}$concentrations after $\mathrm{Na}^{+}$-free cultivation. Difference between $\operatorname{ATR}(-)$ and $\operatorname{ATR}(+): \boldsymbol{b}, F_{(3,44)}=$ $15.47, p<0.0001, k=2,{ }^{* * *} k p<0.0001 ; c, F_{(3,42)}=6.88$, $p=0.0007, k=2,{ }^{*} k p<0.05,{ }^{* * *} k p<0.001 ; \boldsymbol{d}, F_{(3,45)}=$ $29.06, p<0.001, k=2,{ }^{* * * *} k p<0.001 ; \boldsymbol{e}, F_{(3,43)}=71.67$, $p<0.0001, k=2$, ${ }^{* * *} k p<0.001$, one-way ANOVA followed by $t$ test with Bonferroni's correction. $\boldsymbol{f}$, Left, Coexpression of ChR2 and RCaMP2 in ASEL. Middle, Calcium response of ASEL upon ASEL photostimulation in $50 \mathrm{~mm}$ imaging buffer after $\mathrm{Na}^{+}$-free cultivations (optical stimulation strength was 0.5 $\mathrm{mW} / \mathrm{mm}^{2}$, mean $\pm \mathrm{SEM}, n \geq 20$ ). Right, Calcium response change of ASEL neuron (e) (Fig. 4a) during stimulation of ASEL. Difference between two conditions: ${ }^{* * *} p<0.001, t$ test. $g$, Schematic of behavioral response generated by ASEL after $\mathrm{Na}^{+}$-free cultivation. 
a

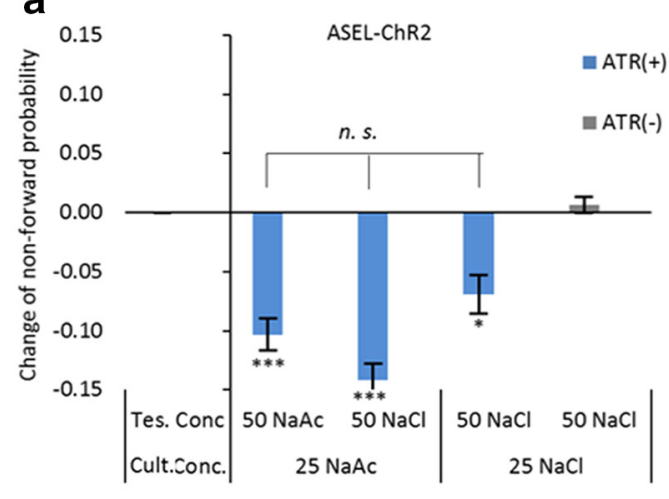

$\mathrm{Na}^{+}$concentration $(\mathrm{mM})$

\section{。}

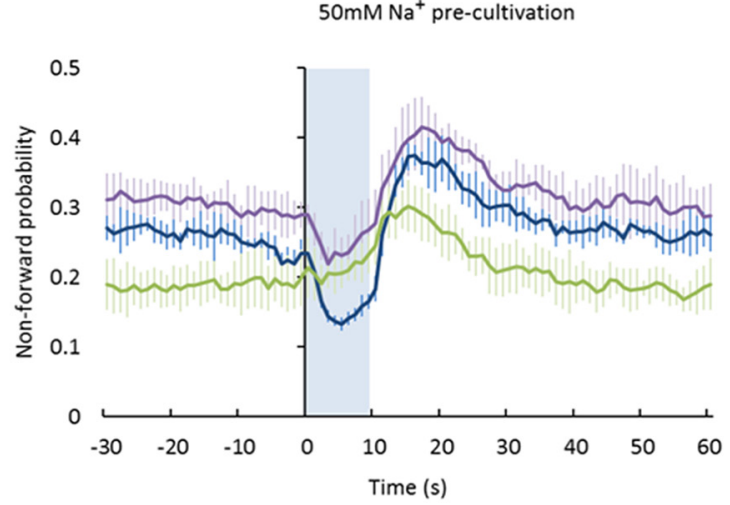

$\longrightarrow d y f-11 ; E x[g c y-7 p:: d y f-11(+)] \longrightarrow d y f-11$

d

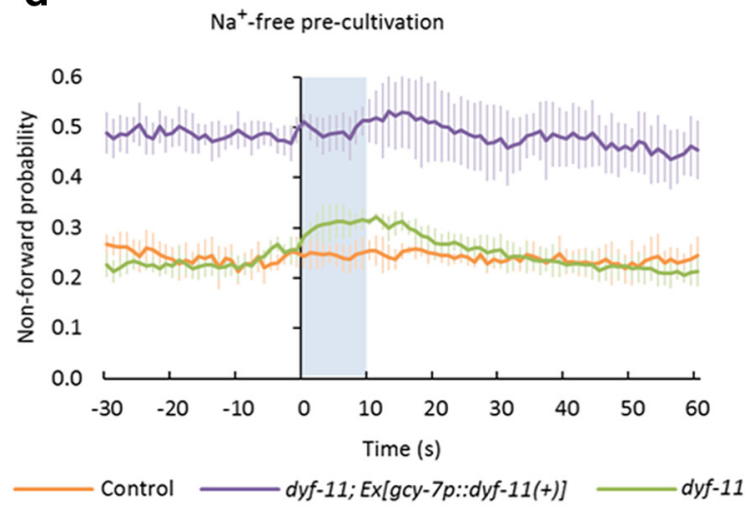

b

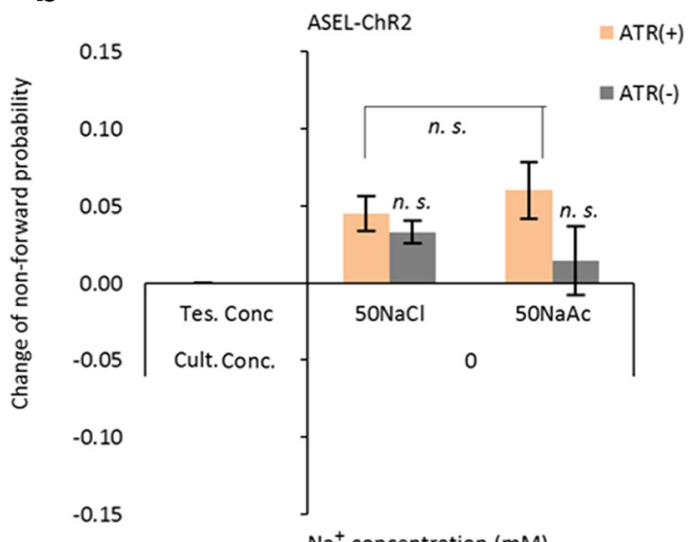

$\mathrm{Na}^{+}$concentration $(\mathrm{mM})$

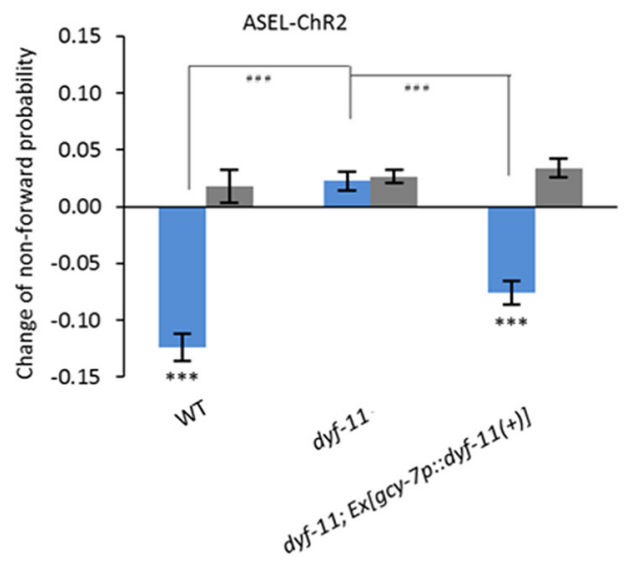

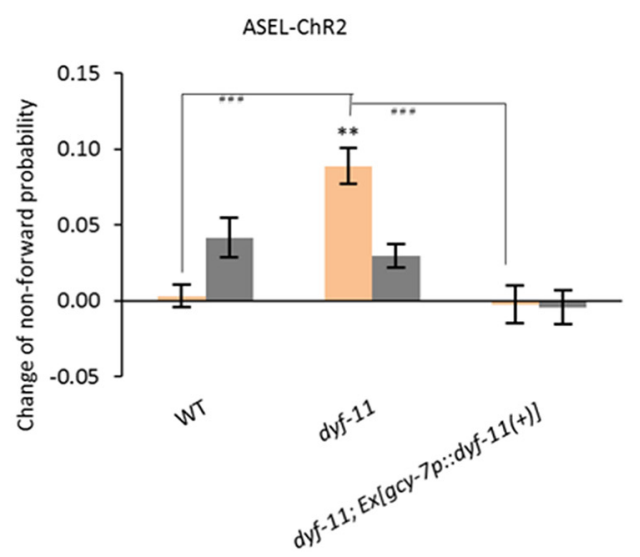

Figure 6. Characterization of ASEL-generated $\mathrm{Na}^{+}$plasticity. $\boldsymbol{a}$, Change of nonforward probability during ASEL stimulation for $60 \mathrm{~s}$ when worms were transferred from $\mathrm{NaAc}$ or $\mathrm{NaCl}$ cultivation to test concentrations with NaAcor NaCl (mean \pm SEM, $n \geq 6$ ). Difference between $\operatorname{ATR}(-)$ and ATR $(+): F_{(3,22)}=13.08, p<0.0001 ;{ }^{*} p<0.05$, ${ }^{* * *} p<0.001$, n.s., no significant difference, one-way ANOVA followed by Bonferroni's multiple comparison. $\boldsymbol{b}$, Change of nonforward probability during ASEL stimulation for $60 \mathrm{~s}$ when worms were transferred from $\mathrm{Na}^{+}$-free cultivation to test concentrations of $25 \mathrm{~mm} \mathrm{NaAc}$ or $25 \mathrm{~mm} \mathrm{NaCl}$ (mean \pm SEM; $n \geq 6$ ). Difference between ATR $\left(-\right.$ ) and ATR $(+): F_{(3,49)}=1.36, p=0.2661, k=2$, n.s., no significant difference, one-way ANOVA followed by $t$ test with Bonferroni's correction. c, Behavioral response (left) and change of nonforward probability (right) of dyf- 11 mutants to ASEL photostimulation in 50 mM Na ${ }^{+}$test concentration after $\mathrm{Na}^{+}$-free cultivation (mean \pm SEM; $n \geq 12$ ). Difference between ATR $(-)$ and ATR $(+): k=3,{ }^{* * *} k p<0.001$; difference between dyf-11 and other strains: \#\#\# $<0.001$, $F_{(5,70)}=44.25, p<0.0001$, one-way ANOVA followed by Bonferroni's multiple comparison. $d$, Behavioral response (left) and change of nonforward probability (right) of dyf-11 mutants to ASEL photostimulation in $100 \mathrm{~mm} \mathrm{Na}^{+}$test concentration after cultivation at $50 \mathrm{~mm} \mathrm{Na}^{+}$(mean $\pm \mathrm{SEM}, n \geq 12$ ). Difference between $\operatorname{ATR}(-$ ) and ATR $(+)$ : $* * 0<0.01$; difference between dyf- 11 and other strains: \#\#\# $<0.001, F_{(5,64)}=10.70, p<0.0001$, one-way ANOVA followed by Bonferroni's multiple comparison.

strain in which egl-30(pe914) was expressed in ASEL, the behavioral response was not observed during or after stimulation of ASEL after cultivation with $\mathrm{Na}^{+}$(Fig. 8b), suggesting that egl-30 negatively regulated the response to ASEL stimulation. After $\mathrm{Na}^{+}$-free cultivation, the transgenic worms showed a small increase of turning behavior during stimulation of ASEL by ChR2 (Fig. 8c). These results also implied that egl-30 regulates $\mathrm{Na}^{+}$chemotaxis, and possibly the behavioral plasticity in $\mathrm{Na}^{+}$chemotaxis, negatively. 
a Cultivation without $\mathrm{Na}^{+}$

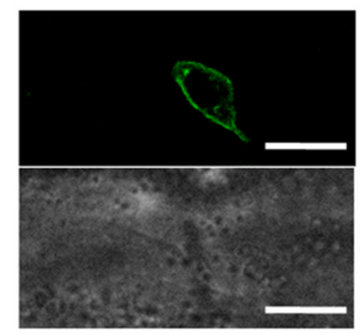

Cultivation with $50 \mathrm{mM} \mathrm{Na}^{+}$

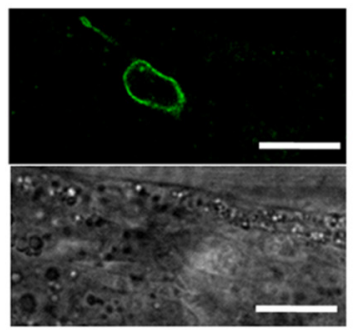

b

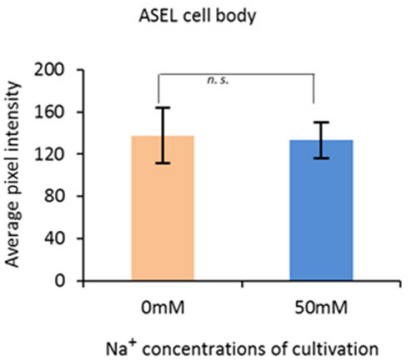

ASEL cell membrane

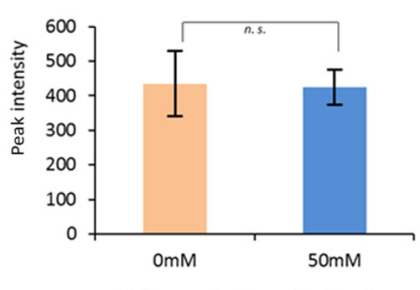

$\mathrm{Na}^{+}$concentrations of cultivation
C

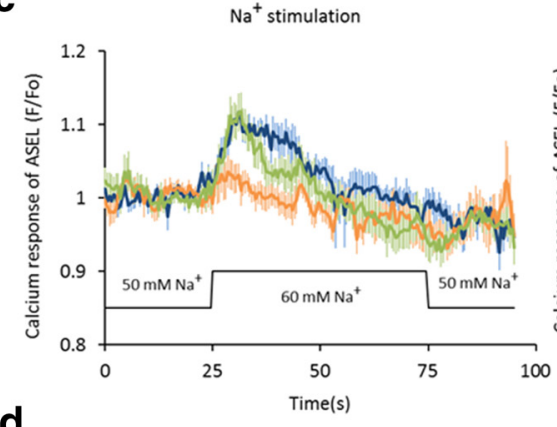

d

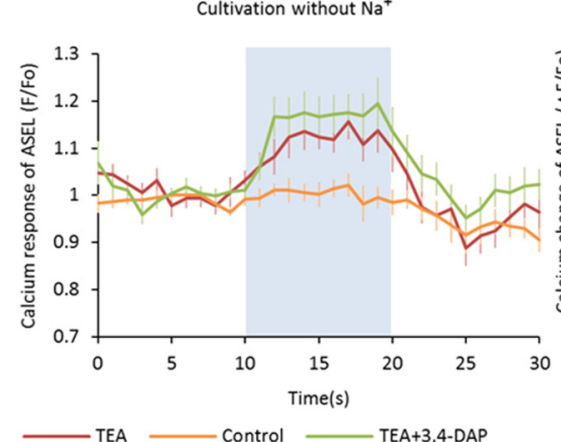

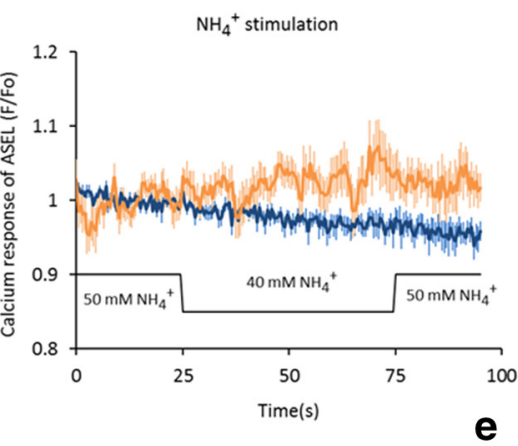

e

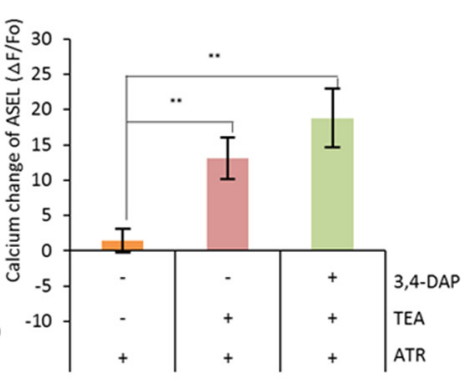

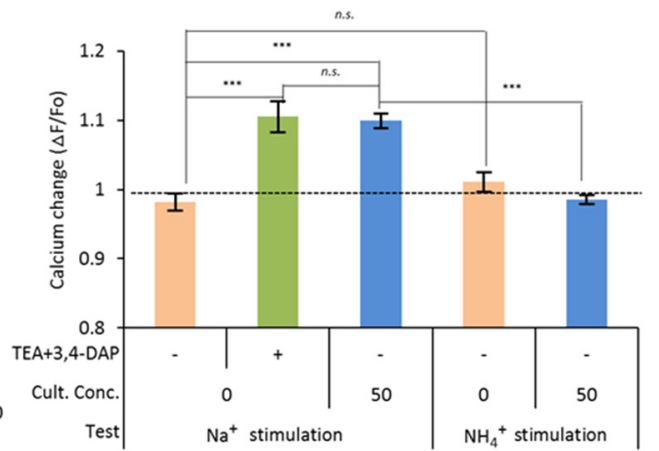

$\mathrm{Na}^{+}$stimulation

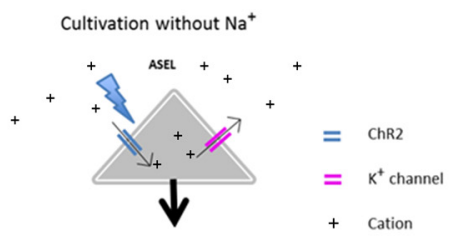

ASEL is not activated

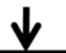

No gradient preference

Figure 7. ASEL's calcium response to $\mathrm{Na}^{+}$and optogenetic stimulation after cultivation without $\mathrm{Na}^{+}$. $\boldsymbol{a}$, Expression patterns of ChR2 in ASEL cell body after cultivation without $\mathrm{Na}^{+}$(left) and with $\mathrm{Na}^{+}$(right). Scale bars, $10 \mu \mathrm{m}$. $\boldsymbol{b}$, Fluorescence intensity of ChR2::Venus in ASEL cell body of adult worms. (mean \pm SEM; $n \geq 22$ ). Left, Average pixel intensity in ASEL cell body ( $p=0.59$, $t$ test). Right, Peak intensity of the membrane of ASEL cell body ( $p=0.92, t$ test). $c$, ASEL's calcium response to $\mathrm{Na}^{+}$concentration changes (mean \pm SEM, $n>10$ ). Left, ASEL's calcium response to $10 \mathrm{~mm} \mathrm{Na}^{+}$upstep (worms were precultivated with $\mathrm{Na}^{+}$(blue line); worms were tested with (green line) and without (orange line) $\mathrm{K}^{+}$channel blocker after cultivation without $\mathrm{Na}^{+}$). Middle, ASEL's calcium response to $10 \mathrm{~mm} \mathrm{NH}_{4}{ }^{+}$down-step. Worms were precultivated with (blue line) or without (orange line) $\mathrm{Na}^{+}$. Right, Averaged fluorescence changes during $5 \mathrm{~s}$ after stimulation for 4 s. Difference among all conditions: $F_{(4,62)}=20.21, p<0.0001,{ }^{* *} p<0.001$, one-way ANOVA followed by Tukey's test). TEA (20 mm) and 3,4-DAP ( 1 mM) were used as $\mathrm{K}^{+}$channel blockers. $\boldsymbol{d}$, ASEL's calcium response (left) and calcium changes (right) to photostimulation at $50 \mathrm{~mm} \mathrm{Na}^{+}$with $\mathrm{K}^{+}$channel blokers after cultivation without Na ${ }^{+}$(mean $\pm S E M ; n \geq 13$ ). Difference of calcium change between conditions of addition with and without $\mathrm{K}^{+}$channel blockers: $F_{(2,46)}=6.864, p=0.0025,{ }^{*} p<0.05,{ }^{* *} p<0.01$, one-way ANOVA followed by Dunnett's test. $e$, Speculated schematic of electrophysiological change in ASEL after cultivation without $\mathrm{Na}^{+}$.

\section{Discussion}

Unexpectedly, we found that ASEL generates a novel type of memory-dependent behavioral plasticity in $\mathrm{Na}^{+}$chemotaxis: when worms were cultivated with $\mathrm{Na}^{+}$, they migrated to higher $\mathrm{Na}^{+}$concentrations (Figs. 1c, $4 f$ ), whereas when cultivated in the absence of $\mathrm{Na}^{+}$and placed in an $\mathrm{Na}^{+}$-containing environment, they showed no $\mathrm{Na}^{+}$concentration preference (Figs. $1 c, 5 g$ ). Behavioral responses to optogenetic activation of the ASEL neuron approximately recapitulated the chemotaxis responses: worms showed no response when they were transferred from $\mathrm{Na}^{+}$-free cultivation to $\mathrm{Na}^{+}$-containing conditions (Fig. $5 a$ ), whereas they showed reduction of turning frequency upon activation of ASEL after cultivation with $\mathrm{Na}^{+}$(Fig. 1e,f). Calcium imaging upon photoactivation or $\mathrm{Na}^{+}$stimulation provided mechanistic insights into this new type of $\mathrm{Na}^{+}$chemotaxis plasticity: ASEL showed no calcium response upon photostimulation or up-step of $\mathrm{Na}^{+}$concentrations after worms were cultivated in $\mathrm{Na}^{+}$-free conditions (Fig. $5 f$ ). As one of the mechanisms for learning and memory, changes in neuronal excitability are well documented, for example, for long-term changes in piriform cortex (Saar and Barkai, 2009), amygdala (Sehgal et al., 2014), and hippocampus in rodents (Gruart et al., 2012). In these events, voltage-gated and leak cation channels are often involved. We found that the calcium response of ASEL was restored in the presence of the $\mathrm{K}^{+}$ channel inhibitors TEA and 3,4-DAP (Fig. 7c,d). There are several possible explanations for these observations. First, cultivation without $\mathrm{Na}^{+}$may cause hyperpolarization of ASEL neuron at the resting states through opening of $\mathrm{K}^{+}$channels, making it more resistant to activating stimuli. Second, the voltage-dependent $\mathrm{K}^{+}$ channel may open when extracellular cations flow into ASEL through ChR2 upon ASEL photostimulation and export intracellular cation in ASEL to keep ASEL's resting membrane potential, 


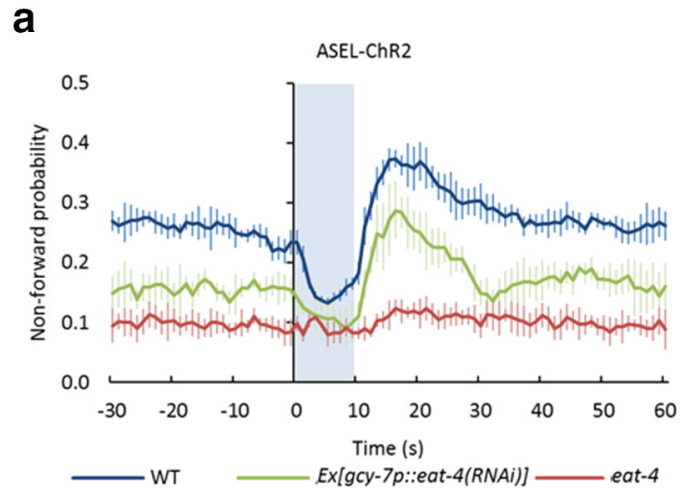

b

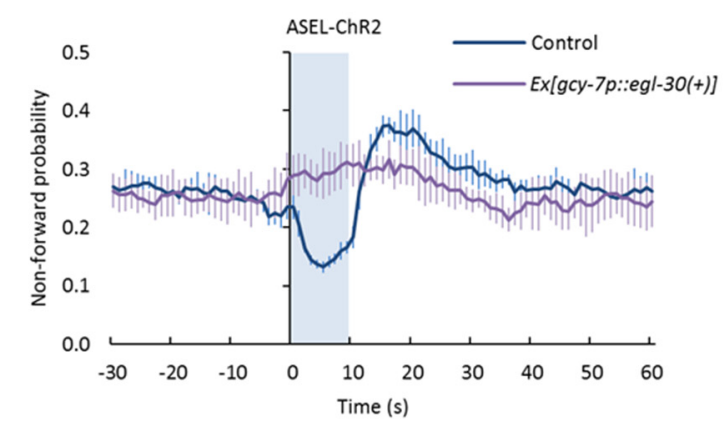

C

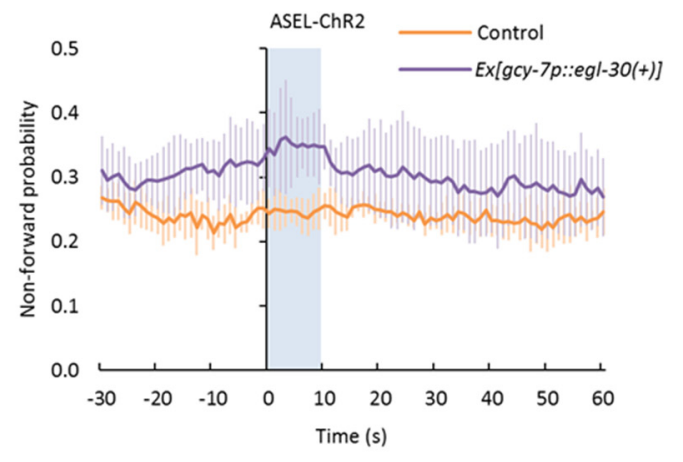

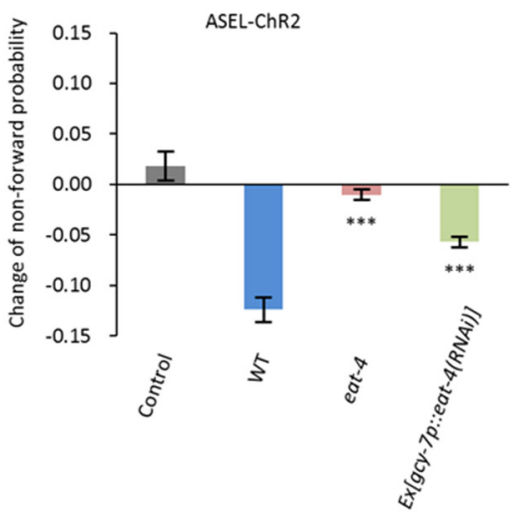

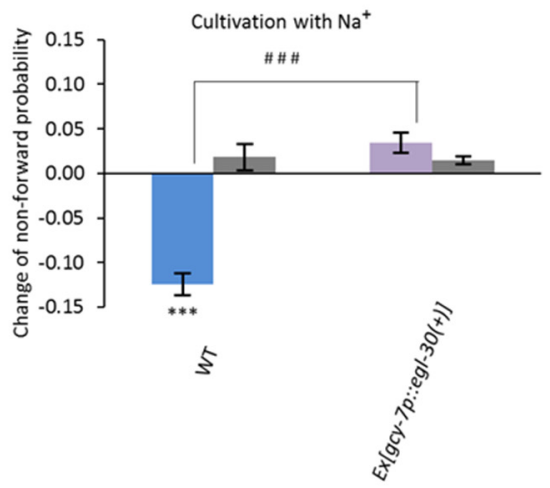

Cultivation without $\mathrm{Na}^{+}$

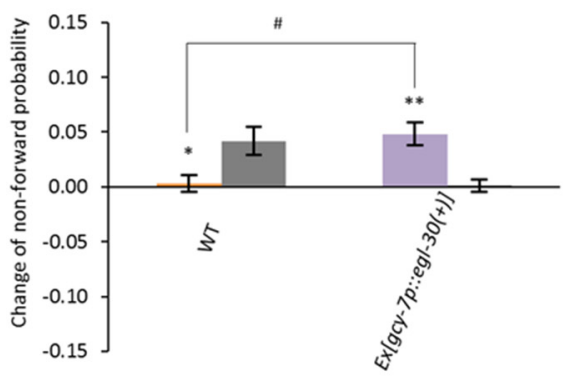

Figure 8. Behavioral response of eat- 4 and egl-30 mutants to ASEL photoactivation. $\boldsymbol{a}$, Behavioral response (left) and change of nonforward probability (right) of eat-4 mutants upon ASEL photoactivation at $100 \mathrm{~mm} \mathrm{Na}^{+}$after $50 \mathrm{~mm} \mathrm{Na}^{+}$cultivation (mean \pm SEM; $n \geq 7$ ). Difference between wild-type and mutants: ${ }^{* * *} p<0.001$, one-way ANOVA followed by Dunnett's test. $\boldsymbol{b}$, Behavioral response (left) and change of nonforward probability (right) of a transgenic strain expressing egl-30 (gf) in ASEL neuron upon ASEL photoactivation in $100 \mathrm{~mm} \mathrm{Na}^{+}$after $50 \mathrm{~mm} \mathrm{Na}{ }^{+}$ cultivation (mean $\pm \mathrm{SEM} ; n \geq 11$ ) Difference between ATR( - ) and ATR( + ): ${ }^{* * *} p<0.001, t$ test. Difference between strains: \#\#\#p $<0.001$, $t$ test. c, Behavioral response (left) and change of nonforward probability (right) of a transgenic strain expressing egl-30 (gf) in ASEL neuron upon ASEL photoactivation in $50 \mathrm{~mm} \mathrm{Na}^{+}$after Na $^{+}$-free cultivation (mean \pm SEM; $n \geq 11$ ). Difference between ATR ( - ) and ATR $(+):{ }^{*} p<0.05,{ }^{* *} p<0.01$, $t$ test. Difference between strains: $\# p<0.05, t$ test.

which in turn makes ASEL more difficult to be excited. Third, more $\mathrm{K}^{+}$ions may leak out of ASEL to shunt the effect of stimulation, which is also considered as reduction in input resistance. No matter which possibility is true, our current findings might be the first discovery of change in intrinsic excitability as a mechanism of cellular plasticity mechanism in neuronal cells in $C$. elegans.

The neural circuits functioning downstream of ASEL are in contrast to those of the well studied AWC neuron, which mediate chemotaxis to odor (Chalasani et al., 2007, 2010). Both AWC neurons and ASE neurons are glutamatergic (Chalasani et al., 2007; Serrano-Saiz et al., 2013) and, as seen in AWC neurons, we found that glutamatergic neurotransmission from ASEL plays an important role in behavioral response for $\mathrm{Na}^{+}$chemotaxis (Fig. $8 a$ ). AWC neurons are activated by odor removal similar to ASER activation by decrease in ion concentration (OFF sensory re- sponse), whereas ASEL is activated by the increase in salt concentration (ON sensory response; Chalasani et al., 2007; Suzuki et al., 2008). Furthermore, all of these sensory neurons send synaptic outputs to the interneurons AIA, AIY, and AIB. However, in contrast to ASEL, AWC releases glutamate to inhibit AIY and AIA while activating AIB to stimulate odor chemotaxis and local search behavior (Chalasani et al., 2007, 2010). Similar to AWC, ASER, also an OFF neuron, activates the interneuron AIB to migrate to higher salt concentrations in salt chemotaxis (Kunitomo et al., 2013). Conversely, ASEL works inversely of AWC in that it activates AIA and AIY and inhibits AIB. Overall, these interneurons are expected to promote migration to higher $\mathrm{Na}^{+}$concentrations given that ASEL shows an $\mathrm{ON}$ response after cultivation with $\mathrm{Na}^{+}$. Our study provides a very interesting cue to understanding what differentiates $\mathrm{ON}$ and OFF sensory neurons even though they use the same interneurons for behavioral response 
and similar neural circuits for regulating chemotaxis. It will be necessary to investigate glutamate receptors acting on the interneurons in the ASEL neural circuit for $\mathrm{Na}^{+}$chemotaxis.

There are multiple behavioral mechanisms and multiple sensory neurons involved in chemotaxis. The calcium level of ASEL was increased by $\sim 10 \%$ as a response to $10 \mathrm{~mm}$ up-step of $\mathrm{Na}^{+}$(Fig. 7c) and $\sim 20 \%$ in response to photostimulation (Fig. $5 f$ ). However, during chemotaxis, worms sense much smaller changes $(<0.06 \mathrm{~mm} / \mathrm{s})$ in $\mathrm{Na}^{+}$concentrations (Fig. $1 d$ ), so the contribution of interneurons might be different. Although ASEL, along with ASER, contributes to both klinokinesis and klinotaxis (Iino and Yoshida, 2009), we only examined the effect of ASEL activation on turning behavior, which is the main component of klinokinesis. AIB, AIY, and AIA are all important interneurons involved in the klinokinesis mechanism (Iino and Yoshida, 2009; Kunitomo et al., 2013). Activation or ablation of each of these neurons affects reversal/turning behaviors (Gray et al., 2005; Kocabas et al., 2012; Kunitomo et al., 2013; this study). AIA laser-ablated worms show a severe defect in the klinokinesis mechanism (Iino and Yoshida, 2009), AIB receives synaptic input from AIA, and both interneurons are involved in klinokinesis (Iino and Yoshida, 2009; Kunitomo et al., 2013). AIB sends synaptic outputs to command interneurons AVA, AVB, and AVE, which regulate forward/reversal locomotion through synaptic outputs to body wall motor neurons, and also to RIM interneurons, which are important for regulation of reversal (Piggott et al., 2011). AIZ interneurons, which receive inputs from AIY, are essential interneurons for the klinokinesis mechanism (Iino and Yoshida, 2009) and are also connected to the command interneurons both directly and indirectly. In addition, head motor neurons are important for the turning behavior. RIA neurons, which receive synaptic inputs from both AIY and AIZ and are connected to SMD and RMD motor neurons, are also important for the klinokinesis mechanism. Therefore, concerted actions of the primary interneurons AIB, AIY, and AIA must be a driving force regulating the klinokinesis mechanism to generate chemotaxis to $\mathrm{Na}^{+}$and other ions and odors.

Our results indicated that the Gq signaling pathway can act in both ASEL and ASER to regulate behavioral plasticity. Upregulation of the Gq signaling pathway in ASER causes worms' attraction to higher $\mathrm{NaCl}$ concentrations, not only in starved conditions (Adachi et al., 2010), but also in well fed conditions (Kunitomo et al., 2013), suggesting that the Gq/PKC pathway has a function in driving worms to higher salt concentrations (Adachi et al., 2010; Kunitomo et al., 2013). Conversely, we showed that activation of egl-30 in ASEL eliminated the promotion of forward movement upon ASEL stimulation after cultivation with $\mathrm{Na}^{+}$(Fig. 8b) and caused weak turning during ASEL stimulation after $\mathrm{Na}^{+}$-free cultivation (Fig. $8 \mathrm{c}$ ), suggesting that the Gq signaling pathway may negatively regulate attraction to $\mathrm{Na}^{+}$after cultivation at high $\mathrm{Na}^{+}$concentrations. In view of the lateralized characteristics of ASE neurons, in which ASEL neurons are activated by an increase of $\mathrm{NaCl}$ concentration whereas ASER neurons are activated by a decrease of $\mathrm{NaCl}$ concentration (Suzuki et al., 2008), it is interesting that the Gq signaling pathway modulates attraction to salts in opposite ways in ASEL and ASER neurons. It would be necessary to investigate the involvement of components of the Gq signaling pathway, such as DAG and $t t x-$ 4/pkc-1, in ASEL for $\mathrm{Na}^{+}$chemotaxis (Brundage et al., 1996; Sieburth et al., 2007; Adachi et al., 2010; Kunitomo et al., 2013).

This is the first report to analyze systematically the characteristics of ASEL, which plays an important role in $\mathrm{Na}^{+}$chemotaxis. The neural mechanisms underlying $\mathrm{Na}^{+}$chemotaxis plasticity is different from $\mathrm{NaCl}$ chemotaxis plasticity mediated by ASER, in which worms get attracted to $\mathrm{NaCl}$ when grown with salt and food (Kunitomo et al., 2013) but avoid $\mathrm{NaCl}$ when starved with $\mathrm{NaCl}$ (Tomioka et al., 2006; Adachi et al., 2010). It also differs from odor chemotaxis plasticity, meaning that, when animals are kept with a certain odor without food, they no longer show attraction to that odor (Colbert and Bargmann, 1995), and from concentration-dependent odor chemotaxis, in which odorsensing neurons switch between high-concentration odor avoidance and low-concentration odor attraction behaviors (Yoshida et al., 2012). All of these chemosensory behaviors are mediated by overlapping neural circuits and our results will extend the platform for further understanding the versatile actions of the small neural circuit of C. elegans.

\section{References}

Adachi T, Kunitomo H, Tomioka M, Ohno H, Okochi Y, Mori I, Iino Y (2010) Reversal of salt preference is directed by the insulin/PI3K and Gq/PKC signaling in Caenorhabditis elegans. Genetics 186:1309-1319. CrossRef Medline

Bargmann, CI (2006) Chemosensation in C. elegans In: WormBook (The C. elegans Research Community, ed). Available online at http://www. wormbook.org. CrossRef

Bargmann CI, Horvitz HR (1991) Chemosensory neurons with overlaping functions direct chemotaxis to multiple chemicals in C. elegans. Neuron 7:729-742. CrossRef Medline

Brenner S (1974) The genetics of Caenorhabditis elegans. Genetics 77:71-94. Medline

Brundage L, Avery L, Katz A, Kim UJ, Mendel JE, Sternberg PW, Simon MI (1996) Mutations in a C. elegans Gq alpha gene disrupt movement, egg laying, and viability. Neuron 16:999-1009. CrossRef Medline

Chalasani SH, Chronis N, Tsunozaki M, Gray JM, Ramot D, Goodman MB, Bargmann CI (2007) Dissecting a circuit for olfactory behavior in Caenorhabditis elegans. Nature 450:63-70. CrossRef Medline

Chalasani SH, Kato S, Albrecht DR, Nakagawa T, Abbott LF, Bargmann CI (2010) Neuropeptide feedback modifies odor-evoked dynamics in Caenorhabditis elegans olfactory neurons. Nat Neurosci 13:615-621. CrossRef Medline

Chandrashekar J, Kuhn C, Oka Y, Yarmolinsky DA, Hummler E, Ryba NJ, Zuker CS (2010) The cells and peripheral representation of sodium taste in mice. Nature 464:297-301. CrossRef Medline

Chronis N, Zimmer M, Bargmann CI (2007) Microfluidics for in vivo imaging of neuronal and behavioral activity in Caenorhabditis elegans. Nat Methods 4:727-731. CrossRef Medline

Colbert HA, Bargmann CI (1995) Odorant-specific adaptation pathways generate olfactory plasticity in C. elegans. Neuron 14:803-812. CrossRef Medline

Daoudal G, Debanne D (2003) Long-term plasticity of intrinsic excitability: learning rules and mechanisms. Learn Mem 10:456-465. CrossRef Medline

Edwards SL, Charlie NK, Milfort MC, Brown BS, Gravlin CN, Knecht JE, Miller KG (2008) A novel molecular solution for ultraviolet light detection in Caenorhabditis elegans. PLoS Biol 6:e198. CrossRef Medline

Frøkjær-Jensen C, Ailion M, Lockery SR (2008) Ammonium-acetate is sensed by gustatory and olfactory neurons in Caenorhabditis elegans. PLoS ONE 3:e2467. CrossRef

Gordus A, Pokala N, Levy S, Flavell SW, Bargmann CI (2015) Feedback from network states generates variability in a probabilistic olfactory circuit. Cell 161:215-227. CrossRef Medline

Gray JM, Hill JJ, Bargmann CI (2005) A circuit for navigation in Caenorhabditis elegans. PNAs 102:3184-3191. CrossRef Medline

Gruart A, Benito E, Delgado-García JM, Barco A (2012) Enhanced cAMP response element-binding protein activity increases neuronal excitability, hippocampal long-term potentiation, and classical eyeblink conditioning in alert behaving mice. J Neurosci 32:17431-17441. CrossRef Medline

Hukema RK, Rademakers S, Jansen G (2008) Gustatory plasticity in C. elegans involves integration of negative cues and $\mathrm{NaCl}$ taste mediated by serotonin, dopamine, and glutamate. Learn Mem 15:829-836. CrossRef Medline

Iino Y, Yoshida K (2009) Parallel use of two behavioral mechanisms for 
chemotaxis in Caenorhabditis elegans. J Neurosci 29:5370-5380. CrossRef Medline

Inoue $\mathrm{M}$, Takeuchi A, Horigane S, Ohkura M, Gengyo-Ando K, Fujii H, Kamijo S, Takemoto-Kimura S, Kano M, Nakai J, Kitamura K, Bito H (2015) Rational design of a high-affinity, fast, red calcium indicator R-CaMP2. Nat Methods 12:64-70. CrossRef Medline

Jones AK, Rayes D, Al-Diwani A, Maynard TP, Jones R, Hernando G, Buckingham SD, Bouzat C, Sattelle DB (2011) A cys-loop mutation in the $C$. elegans nicotinic receptor subunit UNC-63 impairs but does not abolish channel function. J Biol Chem 286:2550-2558. CrossRef Medline

Jospin M, Mariol MC, Ségalat L, Allard B (2002) Characterization of $\mathrm{K}^{+}$ currents using an in situ patch clamp technique in the body wall muscle cells from C. elegans. J Physiol 544:373-384. CrossRef Medline

Kocabas A, Shen CH, Guo ZV, Ramanathan S (2012) Controlling interneuron activity in Caenorhabditis elegans to evoke chemotactic behavior. Nature 490:273-277. CrossRef Medline

Kunitomo H, Iino Y (2008) Caenorhabditis elegans DYF-11, an orthologue of mammalian Traf3ip1/MIP-T3, is required for sensory cilia formation. Genes Cells 13:13-25. CrossRef Medline

Kunitomo H, Sato H, Iwata R, Satoh Y, Ohno H, Yamada K, Iino Y (2013) Concentration memory-dependent synaptic plasticity of a taste circuit regulates salt concentration chemotaxis in Caenorhabditis elegans. Nat Commun 4:2210. CrossRef Medline

Lackner MR, Nurrish SJ, Kaplan JM (1999) Facilitation of synaptic transmission by EGL-30 Gq alpha and EGL- 8 PLC beta: DAG binding to UNC-13 is required to stimulate acetylcholine release. Neuron 24:335346. CrossRef Medline

Larsch J, Flavell SW, Liu Q, Gordus A, Albrecht DR, Bargmann CI (2015) A circuit for gradient climbing in C. elegans chemotaxis. Cell Rep 12:17481760. CrossRef Medline

Lee D, Jung S, Ryu J, Ahnn J, Ha I (2008) Human vesicular glutamate transporters functionally complement EAT-4 in C. elegans. Mol Cells 25:5054. Medline

Lee RY, Sawin ER, Chalfie M, Horvitz HR, Avery L (1999) EAT-4, a homolog of a mammalian sodium-dependent inorganic phosphate cotransporter, is necessary for glutamatergic neurotransmission in Caenorhabditis elegans. J Neurosci 19:159-167. Medline

Leinwand SG, Chalasani SH (2013) Neuropeptide signaling remodels chemosensory circuit composition in Caenorhabditis elegans. Nat Neurosci 16:1461-1467. CrossRef Medline

Li Z, Liu J, Zheng M, Xu XZ (2014) Encoding of both analog- and digitallike behavioral outputs by one C. elegans interneuron. Cell 159:751-765. CrossRef Medline

Liu J, Ward A, Gao J, Dong Y, Nishio N, Inada H, Kang L, Yu Y, Ma D, Xu T, Mori I, Xie Z, Xu XZ (2010) C. elegans phototransduction requires a G protein-dependent cGMP pathway and a taste receptor homolog. Nat Neurosci 13:715-722. CrossRef Medline

Matsuki M, Kunitomo H, Iino Y (2006) Go $\alpha$ regulates olfactory adaptation by antagonizing Gq $\alpha$-DAG signaling in Caenorhabditis elegans. Proc Natl Acad Sci U S A 103:1112-1117. CrossRef Medline

Miller AC, Thiele TR, Faumont S, Moravec ML, Lockery SR (2005) Stepresponse analysis of chemotaxis in Caenorhabditis elegans. J Neurosci 25: 3369-3378. CrossRef Medline

Oda S, Tomioka M, Iino Y (2011) Neuronal plasticity regulated by the insulin-like signaling pathway underlies salt chemotaxis learning in Caenorhabditis elegans. J neurophysiol 106:301-308. CrossRef Medline

Ortiz CO, Faumont S, Takayama J, Ahmed HK, Goldsmith AD, Pocock R, McCormick KE, Kunimoto H, Iino Y, Lockery S, Hobert O (2009) Lateralized gustatory behavior of C. elegans is controlled by specific receptortype guanylyl cyclases. Curr Biol 19:996-1004. CrossRef Medline

Pierce-Shimomura JT, Morse TM, Lockery SR (1999) The fundamental role of pirouettes in Caenorhabditis elegans chemotaxis. J Neurosci 19:95579569. Medline

Piggott BJ, Liu J, Feng Z, Wescott SA, Xu XZ (2011) The neural circuits and synaptic mechanisms underlying motor initiation in C. elegans. Cell 147: 922-933. CrossRef Medline

Rand JB, Duerr JS, Frisby DL (2000) Neurogenetics of vesicular transporters in C. elegans. FASEB J 14:2414-2422. CrossRef Medline

Saar D, Barkai E (2009) Long-lasting maintenance of learning-induced enhanced neuronal excitability: mechanisms and functional significance. Mol Neurobiol 39:171-177. CrossRef Medline

Saeki S, Yamamoto M, Iino Y (2001) Plasticity of chemotaxis revealed by paired presentation of a chemoattractant and starvation in the nematode Caenorhabditis elegans. J Exp Biol 204:1757-1764. Medline

Satoh Y, Sato H, Kunitomo H, Fei X, Hashimoto K, Iino Y (2014) Regulation of experience-dependent bidirectional chemotaxis by a neural circuit switch in Caenorhabditis elegans. J Neurosci 34:15631-15637. CrossRef Medline

Sehgal M, Ehlers VL, Moyer JR Jr (2014) Learning enhances intrinsic excitability in a subset of lateral amygdala neurons. Learn Mem 21:161-170. CrossRef Medline

Serrano-Saiz E, Poole RJ, Felton T, Zhang F, De La Cruz ED, Hobert O (2013) Modular control of glutamatergic neuronal identity in C. elegans by distinct homeodomain proteins. Cell 155:659-673. CrossRef Medline

Sieburth D, Madison JM, Kaplan JM (2007) PKC-1 regulates secretion of neuropeptides. Nat Neurosci 10:49-57. CrossRef Medline

Suzuki H, Thiele TR, Faumont S, Ezcurra M, Lockery SR, Schafer WR (2008) Functional asymmetry in Caenorhabditis elegans taste neurons and its computational role in chemotaxis. Nature 454:114-117. CrossRef Medline

Tomioka M, Adachi T, Suzuki H, Kunitomo H, Schafer WR, Iino Y (2006) The insulin/PI 3-kinase pathway regulates salt chemotaxis learning in Caenorhabditis elegans. Neuron 51:613-625. CrossRef Medline

Ward A, Liu J, Feng Z, Xu XZ (2008) Light-senstive neurons and channels mediate phototaxis in C. elegans. Nat Neurosci 11:916-922. CrossRef Medline

White JG, Southgate E, Thomson JN, Brenner S (1986) The structure of the nervous system of the nematode Caenorhabditis elegans. Philos Trans R Soc Lond B Biol Sci 314:1-340. CrossRef Medline

Yoshida K, Hirotsu T, Tagawa T, Oda S, Wakabayashi T, Iino Y, Ishihara T (2012) Odour concentration-dependent olfactory preference change in C. elegans. Nat Commun 3:739. CrossRef Medline

Zhang YV, Ni J, Montell C (2013) The molecular basis for attractive salttaste coding in Drosophila. Science 340:1334-1338. CrossRef Medline

Zhao Y, Araki S, Wu J, Teramoto T, Chang YF, Nakano M, Abdelfattah AS, Fujiwara M, Ishihara T, Nagai T, Campbell RE (2011) An expanded palette of genetically encoded $\mathrm{Ca}^{2+}$ indicators. Science 333:1888-1891. CrossRef Medline 